\title{
Productivity and Potential Output before, during, and after the Great Recession
}

\author{
John Fernald \\ Federal Reserve Bank of San Francisco
}

September 2012

Working Paper 2012-18

http://www.frbsf.org/publications/economics/papers/2012/wp12-18bk.pdf

The views in this paper are solely the responsibility of the authors and should not be interpreted as reflecting the views of the Federal Reserve Bank of San Francisco or the Board of Governors of the Federal Reserve System. 


\title{
Productivity and Potential Output before, during, and after the Great Recession
}

\author{
John Fernald* \\ Federal Reserve Bank of San Francisco \\ September 26, 2012
}

\begin{abstract}
This paper makes four points about the recent dynamics of productivity and potential output. First, after accelerating in the mid-1990s, labor and total-factor productivity growth slowed after the early to mid 2000s. This slowdown preceded the Great Recession. Second, in contrast to some informal commentary, productivity performance during the Great Recession and early in the subsequent recovery was roughly in line with previous experience during deep recessions. In particular, the evidence suggests substantial labor and capital hoarding. During the recovery, measures of factor utilization fairly quickly rebounded, and TFP and labor productivity returned to their anemic mid-2000s trends. Third, a plausible benchmark for the slower pace of underlying technology along with demographic assumptions from the Congressional Budget Office imply steady-state GDP growth of just over 2 percent per year-lower than most estimates. Finally, during the recession and recovery, potential output grew even more slowlyreflecting especially the effect of weak investment on growth in capital input. Half or more of the shortfall of actual output relative to pre-recession estimates of the potential trend reflects a reduction in potential.
\end{abstract}

JEL Codes: E23, E32, O41, O47

Keywords: Potential output, productivity, business cycles, multi-sector growth models

* Contact email: John.Fernald@sf.frb.org. I especially thank Erik Brynjolfsson, Susanto Basu, Mary Daly, Charles Fleischman, Bob Hall, Bart Hobijn, Òscar Jordà, Kuni Natsuki, Steve Oliner, Nick Oulton, Dan Sichel, John Williams, and Dan Wilson for helpful comments and conversations. I also thank seminar participants at several institutions, as well as other colleagues at the San Francisco Fed. I thank Kuni Natsuki for excellent research assistance, as well as for additional helpful comments. 


\section{Introduction}

This paper looks at the evolution of labor productivity and related growth-accounting variables before, during, and since the Great Recession. A key purpose is to understand how potential output has evolved. In the longer term, potential output plays a central role in determining living standards. In the near term, assessments of potential output play a key role in policy discussions. For example, policymakers and others regularly debate the degree of "slack" in the economy. One measure of slack is the gap between actual output and an estimate of potential. ${ }^{1}$

The story begins before the Great Recession itself. In particular, assessing potential output requires a view on underlying productivity trends. The first point of this paper is that, after accelerating in the mid1990s, underlying productivity growth slowed again after the early to mid 2000s. This slowdown, which preceded the Great Recession but was not widely recognized at the time, is consistent with an apparent reduction in intangible organizational investments associated with information and communications technology (ICT). In particular, ICT has arguably had a broad-based and pervasive effect on measured total factor productivity (TFP) through its role as a general purpose technology (GPT) that fostered complementary innovations, including business reorganization. ${ }^{2}$ The GPT story is essentially one of a drawn-out level effect on productivity — and it appears that, at least for now, the rapid growth effects have ceased.

Did the Great Recession itself change the underlying productivity trends in any important way? If so, it is not yet apparent in the data. In this regard, my second main point is that productivity during and since the Great Recession has largely behaved in line with previous deep recessions. Using a new quarterly growth-accounting dataset described in Fernald (2012) (and summarized in the appendix to this paper), total

${ }^{1}$ See, for example, the blog discussion at http://economistsview.typepad.com/economistsview/2012/02/potential-output-measuring-the-gap.html; or the summary of policymaker views http://www.federalreserve.gov/monetarypolicy/fomcminutes20120125.htm, where "participants expressed a range of views on the current extent of slack in the labor market."

${ }^{2}$ See Brynjolfsson and Hitt (2000), Greenwood and Yorokoglu (1997), and Basu, Fernald, Oulton, and Srinivasan (2003) for discussion of information technology as a general purpose technology. Oliner, Sichel, and Stiroh (2007) provide a careful discussion of the literature, as well as estimates through 2006. 
factor productivity declined 4 percent peak-to-trough during the downturn — the sharpest TFP downturn in the post-war period. Consistent with traditional stories of labor and capital hoarding, measures of utilization also fell sharply. Since the trough, utilization recovered strongly and TFP as well as labor productivity have largely returned to their anemic mid-2000s trends.

During the recession itself, the dip in labor productivity was less pronounced than for TFP. In a growth-accounting sense, the divergence between the sharp TFP decline and the less pronounced decline in labor productivity reflected a surge in capital deepening (especially of structures) and labor quality . Both of these countervailing factors primarily reflect the depth of the recession itself: plunging hours (which raised the capital-labor ratio) and disproportionate job loss by low-skilled workers (which raised the average quality of the labor force).

Informal commentary instead often suggests that productivity performance was unusually strong in the recession and early recovery. Consistent with my results, and in contrast to the informal commentary, Gali, Smets, and Wouters (2012) also point out that productivity performance following the 2007-9 recession has been fairly typical. As a result, they argue this recovery, like the ones that followed the 1990-91 and 2001 recessions, should be described as "slow" rather than "jobless." In the results here, a rebound in factor utilization explains much of the early-recovery surge in labor and total factor productivity.

Even for assessing near-term potential trends, it is useful to have a view on where the economy is going in the longer run. My third point is that, with reasonable estimates of underlying technology trends, a multi-sector neoclassical growth model implies steady-state GDP growth of only 2.1 percent. This estimate incorporates demographic estimates from the Congressional Budget Office (2012), which suggest relatively slow growth in potential hours in the longer term. This 2.1 percent projection appears to be at the low end of recent estimates.

The final point of the paper is that during the recession and recovery itself, potential output growth has run well below even that relatively slow long-run pace. I use the CBO definition of potential, which is essentially a production-function definition. My assessment of recent potential draws on the previous points 
of the paper. Underlying productivity trends have been weak, which implies lower potential growth in the near term as well as the long term. At the same time, capital input has grown at the slowest rate since World War II. This slow growth in productive capacity immediately implies slower growth in the full-employment level of output. (Of course, to the extent that capital formation has been low for cyclical reasons, potential output should rebound somewhat as the economy recovers.) In addition, some temporary labor market disruptions have likely had a modest effect on potential as well.

My estimate of recent trends in potential is somewhat lower than the current CBO (2012) estimates. And the current $\mathrm{CBO}$ estimates themselves are much lower than what the $\mathrm{CBO}$ projected prior to the crisis. In my own estimates, half or more of the shortfall of actual output from the pre-crisis trend reflects a decline in potential output. Nevertheless, actual output does remain well below my subdued current estimate of potential, implying that a sizeable output gap remains.

Section I discusses "facts" about the slowdown in measured labor productivity, as well as the GPT hypothesis for the slowdown. Section II compares the experience during and since the Great Recession to previous recessions and recoveries, finding that productivity experience was comparable. Section III uses a multi-sector growth model to project medium- to long-run potential output growth. Section IV then uses these medium-run trends as well as data on actual capital growth and estimates of full-employment labor to assess where potential currently stands, using the general methodology followed by the Congressional Budget Office.

\section{Productivity Growth before the Great Recession ${ }^{3}$}

Trend productivity growth appeared to slow several years before the Great Recession.

\footnotetext{
${ }^{3}$ See the appendix for a discussion of the data used in this section and the rest of the paper. Note especially that the measure of output used in this paper combines the expenditure and income sides of the accounts, so that labor productivity differs slightly from the BLS productivity and cost release (which uses expenditure-side data). None of the results in the paper appear particularly sensitive to combining the two measures.
} 


\section{A. The mid-2000s Slowdown in Labor Productivity Growth}

Figure 1 shows the log-level of labor productivity for the business sector starting after the wellknown slowdown in 1973. The speedup in growth during the mid-1990s is clear. ${ }^{4}$ Considerable literature has highlighted the role of information and communications (ICT) in explaining the mid-1990s acceleration. ${ }^{5}$

The striking feature of Figure 1 is that the mid-1990s acceleration in labor productivity ended in the early- to mid-2000s. The vertical bars show the dates chosen from a Bai-Perron test for multiple structural change in mean growth rates for the period since 1973. The dates chosen for the new regimes are 1997:Q2, and 2003:Q4. The breaks are statistically significant. ${ }^{6}$ From 2003:Q3 through 2012:Q2, ${ }^{7}$ labor productivity in the business sector has grown at only 1.6 percent per year, down from a rate of 3.6 percent from 1997:12003:3. Indeed, the recent pace is comparable to the 1.5 percent average growth in labor productivity from 1973:2 through 1997:1. ${ }^{8}$

The Bai-Perron results that show a slowdown in the early to mid-2000s echo the findings of Kahn and Rich (2011). They estimate a regime-switching model, using data on labor productivity, labor compensation, and consumption. They find that productivity switched from a high-growth to a low-growth regime around 2004.

${ }^{4}$ Fernald (2007) discusses the statistical evidence as of the mid-2000s for the speedup.

${ }^{5}$ For example, Oliner and Sichel (2000) and Jorgenson (2000) emphasize the accumulation of ICT capital; Basu, Fernald, Oulton, and Srinivasan (2003) emphasize intangible investments in organizational capital related to ICT. Oliner, Sichel, and Stiroh (2006) review this literature.

${ }^{6}$ The test assumes growth rates are stationary, and tests whether mean growth (the drift term for a random walk series) has breaks. For the sample from 1973:Q1 through 2012:Q2, the Bai-Perron WDmax test of the null of no breaks against an alternative of an unknown number of breaks rejects the null at the 1 percent level. The UDmax version of the same test rejects the null at the 2.5 percent level. The highest significance level is for the null of no breaks against the alternative of 2 breaks, which is significant at the 1 percent level. In the full sample from 1947:Q1 on, there appears to be an additional break at 1973:Q2, as expected. 2003:Q4

${ }^{7}$ To be clear on dating conventions, "from 2003:Q3" means average (logarithmic) growth rates starting in

${ }^{8}$ All percent changes in this paper are calculated as 100 times the change in natural logs. 


\section{B. Growth Accounting Identities}

Growth accounting provides a perspective on the forces explaining the slower pace of productivity growth. To fix concepts, suppose there is a constant returns aggregate production function for output, $Y$ :

$$
Y=A \cdot F\left(W \cdot K\left(K_{1}, K_{2}, \ldots\right), E \cdot L\left(H_{1}, H_{2}, \ldots\right)\right)
$$

A is technology. $K$ and $L$ are observed capital and labor input. $W$ is the workweek of capital and $E$ is effort. $W$ and $E$ thus represent unobserved variation in the utilization of capital and labor. $K_{i}$ is input of a particular type of capital - computers, for example, or office buildings. Similarly, $H_{i}$ is hours of work by a particular type of worker, differentiated by skills, education, age, and so forth. Time subscripts are omitted for notational simplicity.

The first-order conditions from cost-minimization imply that output elasticities for a given type of input are proportional to shares in cost. Let $\alpha$ be total payments to capital as a share in total costs and $c_{i}^{j}, j \in K, L$, be the shares in the total costs of capital and labor, so that $\sum_{i} c_{i}^{j}=1, j \in K, L$. Then, for example, the output elasticity for a given type of capital is $\alpha c_{i}^{K}$. Differentiating logarithmically (with hats representing log-changes in a variable), and imposing the first-order conditions yields: ${ }^{9}$

$$
\begin{aligned}
\hat{Y} & =\alpha \hat{K}+(1-\alpha)(\hat{H}+\widehat{L Q})+\widehat{U t i l}+\hat{A} \\
& =\alpha \hat{K}+(1-\alpha) \hat{L}+\widehat{U t i l}+\hat{A}
\end{aligned}
$$

where various input aggregates on the right-hand-side are defined as: :

${ }^{9}$ See, for example, Basu and Fernald (2002) for derivations and discussion of how to interpret measured TFP when constant returns, perfect competition, and the assumed existence of an aggregate production function do not apply. With a first-order approximation (equivalently, if the aggregate production function is Cobb-Douglas), the shares are constant over time. A Tornquist approximation to equation (1) - which uses log-growth rates of all quantities, and where shares are time-varying averages in periods $t$ and $t-1$ - is exact for the translog functional form, which provides a second-order approximation to any general production function (see Diewert, 1976). 


$$
\begin{aligned}
& \hat{K} \equiv c_{1}^{K} \widehat{K_{1}}+c_{2}^{K} \widehat{K_{2}}+\ldots, \\
& \hat{L} \equiv c_{1}^{L} \hat{H}_{1}+c_{2}^{L} \hat{H}_{2}+\ldots \\
& \hat{H} \equiv \hat{H}_{1}+\hat{H}_{2}+\ldots \\
& \widehat{L Q} \equiv \hat{L}-\hat{H} \\
& \widehat{U t i l} \equiv \alpha \hat{W}+(1-\alpha) \hat{E}
\end{aligned}
$$

Growth in capital services, $\hat{K}$, is share-weighted growth in the different types of capital goods; growth in labor services, $\hat{L}$, is share-weighted hours growth by different types of workers. Total hours growth, $\hat{H}$, is the simple sum of hours worked by all types of labor. Labor quality growth, $\widehat{L Q}$, captures the productive benefits of changes in composition of hours worked and is defined so that growth in labor input is the sum of growth in hours and growth in labor quality. Finally, $\widehat{\text { Util }}$ represents variations in capital's workweek and labor effort.

Observed total factor productivity (TFP) growth, the Solow residual, is output growth not explained by growth in observed inputs:

$$
\begin{aligned}
\widehat{T F P} & \equiv \hat{Y}-\alpha \hat{K}-(1-\alpha) \hat{L} \\
& =\widehat{U t i l}+\hat{A}
\end{aligned}
$$

The second line follows from equation (1). A large literature discusses reasons why measured TFP change might not measure technology change in practice. ${ }^{10}$ Over the business cycle, a key reason, reflected in $\widehat{U t i l}$, is unobserved variations in the intensity with which factors are used. For example, such variations might reflect incentives to hoard labor in a downturn. Basu, Fernald, and Kimball (BFK, 2006) implement a theoretically based measure of utilization. In practice, their method essentially involves rescaling variations in detrended hours per worker.

From (1) and (3), labor productivity growth, defined as growth in output per hour, is then:

\footnotetext{
${ }^{10}$ See Basu and Fernald (2002 and 2006) for extensive discussion and references.
} 


$$
\begin{aligned}
\hat{Y}-\hat{H} & =\alpha(\hat{K}-\hat{H}-\widehat{L Q})+\widehat{L Q}+\widehat{U t i l}+\hat{A} \\
& =\alpha(\hat{K}-\hat{H}-\widehat{L Q})+\widehat{L Q}+\widehat{T F P}
\end{aligned}
$$

Loosely speaking, labor productivity rises in the long run if workers have more capital to work with; if their quality improves; or if innovation raises technology. In the short run, cyclical variations in utilization also affect labor productivity.

\section{Data and Growth-Accounting Results}

This section implements the decomposition in equation (4) using a new quarterly growth-accounting dataset described in Fernald (2012), and briefly described in the appendix. These data provide quarterly business-sector growth accounting components, and are posted online with only a short lag. The data show that slower growth in both TFP and capital deepening contributed to the mid-2000s slowdown in labor productivity growth.

Figure 2 shows the components on the right-hand side of equation (4) as well as utilization change. All are measured in log-levels (i.e., cumulated changes in logs), which makes it easier to see trends. The utilization measure follows BFK as applied to quarterly data. BFK consider a more general framework than in Section I.B to allow for non-constant returns, imperfect competition, and cyclical reallocation effects on productivity measures. Because of data limitations in quarterly data, however, the Fernald measure used here controls only for utilization change. For this reason, Fernald refers to the empirical counterpart to $\hat{A}$ as utilization-adjusted TFP.

In a growth accounting sense, the figure shows a slowdown in both TFP and capital deepening around the time of the mid-2000s slowdown in labor productivity growth. Panel A shows TFP and utilization-adjusted TFP. The eye clearly identifies a slowdown in the early to mid-2000s. ${ }^{11}$ Panel B shows capital-deepening, $K /(H \cdot L Q)$. In the early 2000 s, capital deepening leveled out and, hence, also

\footnotetext{
${ }^{11}$ A Bai-Perron test does not show the slowdown to be significant, reflecting the volatility of the series. (As is well known, the test is not particularly powerful.)
} 
contributes to the slower growth in labor productivity. Panel C shows labor quality, which has risen steadily and, indeed, accelerated in the Great Recession. Finally, Panel D shows utilization itself. This series is clearly highly cyclical. By 2012:Q2, this measure suggests that utilization has rebounded to a level close to its pre-recesssion peaks-indeed, somewhat above its longer-run mean. ${ }^{12}$

I look more closely at the experience during and since the Great Recession in Section II. But it is worth noting that in Figure 1 (for labor productivity) or Figure 2.A (for TFP), productivity as of mid-2012 appears to lie more or less on the slow trend line from the mid-2000s.

\section{Explaining the Slowdown in Trend Labor Productivity}

Why did productivity growth slow in the mid-2000s? A large literature explains the earlier productivity acceleration of the late 1990s in terms of the direct and indirect effects of information and communications technology (ICT). This section emphasizes the converse: If the rapid pace of ICT gains came to an end, then it would naturally show up in both TFP and capital-deepening. Specifically, the data are consistent with the view that productivity slowed in the 2000s because of the waning of the exceptional growth effects of information technology as a general purpose technology (GPT).

To understand this hypothesis, it is worth thinking about why productivity growth sped up in the mid-1990s and, further, in the early 2000s. ${ }^{13}$ ICT was the obvious suspect, as computers and the Internet became increasingly pervasive. As Jorgenson (2000) and others emphasized, in a neoclassical framework, technological progress in the production of a capital good like ICT has two effects on labor productivity.

First, to the extent that ICT goods are domestically produced, it increases $\widehat{A}$ directly. Second, it lowers the user cost of capital, and induces greater capital-deepening in ICT-using sectors.

\footnotetext{
${ }^{12}$ The level at the end point is a bit uncertain because the measure comes from industry hours per worker, which need to be detrended. This measure uses a bandpass filter to remove fluctuations at frequencies beyond 32 quarters, and detrending is inherently uncertain at end points.

${ }^{13}$ Oliner, Sichel, and Stiroh (2007) provide a nice summary of potential explanations, with copious references.
} 
Both factors are apparent in the industry data. But they aren't the whole story, since measured TFP growth increased broadly_-in ICT-using, as well as ICT-producing, sectors (see, for example, Basu, Fernald, Oulton, and Srinivasan, BFOS, 2003). Stories of ICT as a GPT provide an explanation. As emphasized by Greenwood and Yorokoglu (1997), Brynjolfsson and Hitt (2000), and BFOS, faster ICT and (starting in the 1990s) the Internet induced firms to invest in intangible, complementary organizational capital to take advantage of faster informational processing. BFOS discuss how to map GPT stories into conventional growth accounting. The story is one of intangible investment. ${ }^{14}$ When firms are investing in intangible organizational or other capital, measured productivity declines as firms divert resources to unobserved investment. With a lag, firms get the benefits of the accumulated intangible capital and measured productivity rises.

BFOS derive an observable proxy for intangible investment associated with ICT: Growth in ICT capital, weighted by share of payments to ICT capital in total production cost. The intuition is straightforward. First, the link from unobserved intangible organization investment to observed ICT growth comes from the evidence that expansions of ICT capital are associated with a increases in complementary reorganizations to take advantage of the information processing (see Brynjolfsson and Hitt, 2000). Second, the share weight comes from the fact that we need to account for the scale or magnitude of the intangible investments. For example, suppose firms don't use much ICT capital, as reflected in a small share. Then, for any given growth rate of ICT capital, unobserved IT-related reorganizations are less likely to a quantitatively important source of mismeasurement of productivity than if the firm uses a lot of ICT capital.

Figure 3 shows the aggregate value of this proxy. It peaks around 2000 and then falls off. In the BFOS/intangibles story, true productivity growth was even faster than measured in the late 1990s as firms diverted resources to reorganization. In the early 2000 s, ICT investment plunged-but, as noted earlier, measured productivity growth remained strong (or even rose). This is consistent with firms no longer

\footnotetext{
${ }^{14}$ See Corrado, Hulten, and Sichel (2009) for a more general discussion of intangible investment.
} 
diverting resources to intangible investment, which temporarily boosts measured productivity. With a lag, however, productivity growth in this story would end. As Oliner, Sichel, and Stiroh (2007) note:

...intangible investment has been quite sluggish since 2000, coinciding with the soft path for IT capital spending. All else equal, this pattern could be a negative for labor productivity growth in the future to the extent that these investments are seed corn for future productivity gains.

Fundamentally, the rapid pace of GPT benefits of information technology on growth had to end sometime. It was just hard to know ex ante when the slowdown would take place. It is plausible that the low-hanging fruit was plucked by the mid-2000s. ${ }^{15}$

\section{Productivity Growth during the Great Recession}

This section turns to the more recent productivity experience. Specifically, how unusual was the behavior of productivity during the Great Recession? This section argues that during and immediately after the Great Recession, the behavior of productivity has been in line with previous deep recessions. In particular, TFP and utilization fell very sharply during the recession, and recovered strongly once the recession ended. Labor productivity has evolved similarly to previous deep recessions. This conclusion contrasts with many informal discussions, which suggest that labor productivity was surprisingly strong during and immediately after the Great Recession.

Figures 4 and 5 show "spider charts" comparing the Great Recession to the nine previous recessions $(1953-2001)^{16}$. In each panel, the horizontal axis shows the number of quarters from the peak. In the Great Recession, for example, quarter 0 corresponds to 2007:Q4. Panel A of Figure 4 shows that the experience of labor productivity is quite similar to previous deep recessions in 1973-75 and 1981-82. Notably, labor productivity is at the bottom of the historical experience. Of course, output fell far more than in previous downturns (Panel B). And hours worked fell by an exceptional amount (Panel C).

\footnotetext{
${ }^{15}$ Robert Gordon has long expressed skepticism that information technology measured up to previous great inventions. See, for example, Gordon (2010).

${ }^{16}$ The experience for the 1980 recession is truncated at quarter 5, when it would run into the 1981-82 recession.
} 
In contrast to what these figures show, many commentators have suggested that productivity was, in fact, surprisingly strong during the recession and recovery. For example, because of extraordinary fear and concern in late 2008 and early 2009, firms may have cut workers more sharply and earlier, relative to previous deep recessions. If this were the case, then they might not have hoarded labor in the usual way-so intensity margins (observed, such as hours per worker, or unobserved utilization) should not have been used as much. It is true that labor fell by an exceptional amount. But firms also made substantial use of the intensity margin: The BFK measure of utilization in Figure 5.D, which is a mapping from observed hours per worker, fell more than in any previous post-war recession and then recovered very sharply during the recovery. ${ }^{17}$

TFP provides a complementary perspective on the intensity story that does not depend on a specific measure of factor utilization. Specifically, if labor productivity behaved unusually because firms didn't hoard labor, then TFP should not have fallen as much as in previous recessions. But Figure 4.D shows that TFP did, in fact, fall by more than in any previous recession. When the recovery took hold, TFP then bounced back.

From a growth-accounting perspective, why was the TFP decline even more pronounced than the labor productivity decline, relative to previous downturns? Consistent with equation (4), both capital deepening and labor quality were strongly positive. Panel A of Figure 5 shows that capital input growth has been extraordinarily weak. Indeed, in the depth of the recession, capital stopped growing entirely (for the first time in the post-war period). But of course, labor also fell very sharply, and Panel B shows that the capital-labor ratio rose very sharply. This supported labor productivity relative to TFP. Panel C shows that labor quality also rose more quickly than in previous downturns, as low skilled/low education workers

${ }^{17}$ Recent papers have highlighted that, in recent decades, labor productivity is no longer procyclical; see, e.g., Gali and van Rens (2010) for references. This "vanishing procyclicality" holds in my data, reflecting reduced variability in utilization relative to total hours worked. The Great Recession, however, saw exceptionally large variations in the intensity (utilization) margin. 
disproportionately lost jobs. This also supported output per hour relative to TFP. The capital-deepening and labor-quality effects partially offset the sharp decline in utilization shown in panel D.

Gali, Smets, and Wouters (2012) focus on the recovery and, as I do, argue that, following the Great Recession, productivity performance was in line with historical experience. Specifically, they look at the experience in the three so-called "jobless recoveries" following the recessions of 1990-91, 2001, and 2007-9. They argue that these recoveries are not jobless, per se, in that the relationship between employment and GDP has been fairly stable. Rather, these recoveries should be characterized as "slow."

Their finding is consistent with the pattern in Figure 4. But to focus more specifically on recoveries alone, Figure 6 indexes to the trough rather than to the peak. Figure 6 shows clearly that, in the first five or so quarters of the recovery, labor productivity and TFP performed similarly to previous recoveries. The anomaly, rather, is the "flat spot" in productivity that begins in the end of 2010, roughly six quarters into the recovery. TFP is at the bottom of the band of historical experience, whereas labor productivity is slightly below historical experience (in part reflecting that capital-deepening, panel E, has fallen below historical experience).

Unfortunately, the flat spot does not appear to be an anomaly, or "payback" from unusual experience early in the recession. Rather, looking back at Figure 1, TFP growth paused in the mid-2000s. From the broader perspective, the "flat spot" appears to reflect the slow underlying trend. Indeed, the experience is reminiscent of the experience in the 1970s, when utilization-adjusted TFP in 1983 was only at its 1975 level; standard TFP shows a similar pattern. (Reassuringly, TFP growth subsequently picked up again in the 1980s - it did not permanently stagnate. Nevertheless, the entire 1973-97 period was disappointing.)

Did the Great Recession itself affect TFP growth? For example, it could have affected reallocation of capital towards higher productivity firms. Informational and contractual frictions, including financing constraints, are important in reallocating capital efficiently (see, for example, Eisfelt and Rampini, 2006). In the past few years, some businesses have certainly faced financing constraints. In addition, firms may have cut back on research and development and other investments in innovations that did not offer rapid 
payback. ${ }^{18}$ From 2003:3-2007:4, utilization-adjusted TFP growth averaged only a 0.2 percent pace; since then, it has averaged a 0.4 percent pace. There is little evidence in these figures that there was a further influence of the Great Recession on underlying TFP growth, as opposed to there simply being an anemic underlying pace of growth. ${ }^{19}$

Finally, real-time data obscured the slowdown in trend, and overstated productivity's strength early in the Great Recession. Figure 7 shows that almost every revision since 2005 has lowered the path of labor productivity. The real-time data obscured the weakness in labor productivity growth after 2003 . In addition, the real-time data also overstated the strength of labor productivity growth early on in the recession. Thus, data revisions help explain some of the disconnect between perceptions of recent productivity performance and the disappointing reality.

\section{Potential Output Growth after the Great Recession}

What are its prospects for potential growth going forward? I begin by projecting labor productivity and potential output in the medium to long run. In the long run, potential output depends on supply-side factors: What the economy can produce using actual capital input (at normal, or steady-state, utilization); with labor input at its steady-state level; and with available technology. Rearranging equation (4), potential output growth can be decomposed into growth in labor productivity and labor input:

$$
\hat{Y}^{*}=\underbrace{\left[\alpha\left(\hat{K}-\hat{H}^{*}-\widehat{L Q}^{*}\right)+\hat{A}^{*}\right]}_{\text {potential labor productivity growth }}+\underbrace{\left[\hat{H}^{*}+\widehat{L Q}^{*}\right]}_{\text {quality-adjusted hours growth }}
$$

Stars $\left(^{*}\right)$ denote potential or steady-state values. The term $\left(\hat{K}-\hat{H}^{*}-\widehat{L Q}^{*}\right)$ represents steady-state capital deepening.

${ }^{18}$ Patent applications, for example, were flat from 2007-2009 before ticking up. Real R\&D spending fell from 2008 to 2009 (the last year available as of this writing).

${ }^{19}$ Standard TFP growth, it should be noted, slowed from a 0.8 percent pace from 2003:3-2007:4 to only 0.2 percent since 2007:4. However, utilization looks to have run up prior to the recession, which boosted the pre-recession TFP figures. 
What follows generally assumes constant returns and perfect competition and that utilization has a zero steady-state growth rate. Hence, steady-state growth in technology and measured TFP are equal: $\hat{A}^{*}=\widehat{T F P^{*}}$.

\section{A. Multi-Sector Projections of Labor Productivity Growth}

I use a neoclassical growth model to project business-sector labor productivity. As is well known, capital-deepening in the one-sector neo-classical growth model (e.g., the Solow model) depends on exogenous TFP growth (see Appendix B). In the steady state of that model, the capital-output ratio is constant.

In U.S. data, however, the capital-output ratio is not constant but has an upward trend. The literature on multi-sector models, where one (or more) sector produces investment goods and other sectors do not, makes clear that the final-use sector matters. In particular, in the multi-sector neoclassical model, capital deepening depends solely on TFP in the investment sector (see the appendix, or Basu and Fernald 2009). Potential labor productivity in equation (5) can then be expressed as:

$$
\hat{Y}^{*}-\hat{H}^{*}-\widehat{L Q}^{*}=\widehat{T F P}+\alpha \cdot \widehat{T F P} /(1-\alpha) .
$$

The basic multi-sector model assumes that all capital goods are reproducible. In practice, land is also an important input: In the post-war period, it averages about 16 percent of capital payments; over the past decade, it has averaged about 12 percent. In the case with exogenous land, the appendix shows that the equation is modified to be:

$$
\hat{Y}^{*}-\hat{H}^{*}-\widehat{L Q}^{*}=\widehat{T F P}+\left[\frac{\alpha\left(1-c_{T}\right)}{1-\alpha\left(1-c_{T}\right)}\right] \widehat{T F P}+\left(\frac{\alpha c_{T}}{1-\alpha\left(1-c_{T}\right)}\right)\left(\hat{T}^{*}-\hat{H}^{*}-\widehat{L Q}^{*}\right)
$$

In this equation, $\hat{T}^{*}$ is the growth rate of land (with mnemonic $T$ for Terra), and $c_{T}$ is the share of payments to land in capital income. The first two terms are similar to the case without land, and reflect that capital deepening again depends on TFP in the investment sector. However, the capital-deepening effect (the weight on $\widehat{T F P}$ ) is slightly attenuated relative to the no-land case. 
The final term depends on the growth rate of land relative to labor. This term is small, averaging about 0.03 percentage points over the full sample. Land's share in total capital income, $\alpha c_{T}$, averaged about 0.05 and $\left(\hat{T}^{*}-\hat{H}^{*}-\widehat{L Q}^{*}\right)$ has typically run in the range of $1 / 2$ to 1 percent per year. (The BLS estimates that land input used in the private business sector rose at 1.4 percent per year from 1987-2009. ${ }^{20}$ )

To implement this steady-state decomposition, I assume there are three final-use sectors that use capital and labor (which grows exogenously) to produce output:

$$
\begin{aligned}
& D=\left(K_{D}\right)^{\alpha}\left(A N_{E}\right)^{1-\alpha} \\
& B=Q_{B}\left(K_{B}\right)^{\alpha}\left(A N_{B}\right)^{1-\alpha} \\
& C=Q_{C}\left(K_{C}\right)^{\alpha}\left(A N_{C}\right)^{1-\alpha}
\end{aligned}
$$

The first sector produces Durable goods: equipment, consumer durables, and inventories. The second sector produces Buildings or structures. The third produces non-durables and services for Consumption or government. The production functions are identical apart from building-specific and consumption-specific technology shocks, $Q_{B}$ and $Q_{C}$.

Some durable goods are invested and become equipment capital. (Non-structure) durable goods are invested and become equipment capital according to the usual perpetual inventory equation. All new buildings become structures. Land grows exogenously. All three sectors use the same capital aggregate, which uses equipment $E$, structures $S$, inventories $V$, and land $T$.

$$
K=E^{c_{E}} S^{1-c_{E}-c_{V}-c_{T}} V^{c_{V}} T^{c_{T}}=K_{D}+K_{B}+K_{C}
$$

The appendix discusses the general properties of this model. To summarize the main theoretical and empirical reasons for this implementation:

- Theory tells us that investment TFP determines capital-deepening

- Investment itself is heterogeneous. Most notably, the price of equipment, especially but not solely information-technology related, has fallen rapidly relative to the prices of other goods. In contrast, the relative price of structures has risen modestly but steadily over time.

${ }^{20}$ BLS tables on "Capital by Asset Type for Major Sectors" at http://www.bls.gov/mfp/mprdload.htm, vintage March 30, 2011 (downloaded March 16, 2012). 
- Since 1947, land's share in capital payments has averaged 16 percent. So land is sizeable. In the BLS capital tables, the correlation of annual changes in land and structures is about 0.4. This correlation is sizeable, but far from perfect. In other words, land does not move systematically with structures or other types of capital. We take it as exogenous.

- Inventories' share of capital payments averages 12 percent —also sizeable. About half of NIPA inventories are classified as "durable" and half as "nondurable." Nevertheless, I assume that inventories are produced by the durable sector, since the majority of what is classified as "consumption" (i.e., business output other than equipment, consumer durables, and structures) is services rather than goods. ${ }^{21}$ (The general predictions are similar if I take inventories to be produced by the consumption sector.)

To identify sectoral technology growth, I use relative prices from the NIPAs. ${ }^{22}$ The output price in each sector is a markup, $\mu$, over marginal cost, $M C$. So the relative price of, say, consumption to durable equipment is:

$$
\widehat{P_{C}}-\widehat{P_{D}}=\left(\widehat{\mu_{C}}+\widehat{M C_{C}}\right)-\left(\widehat{\mu_{D}}+\widehat{M C_{D}}\right)
$$

With identical production functions and factor prices, marginal cost depends solely on relative technologies. With perfect competition, the markups both equal one and, hence:

$$
\widehat{P_{C}}-\widehat{P_{D}}=\widehat{A^{D}}-\widehat{A^{C}}=-\widehat{Q_{C}}
$$

As a caveat, measured relative prices are an imperfect measure of relative technology in practice. Especially in the short run, utilization change, non-constant returns to scale, or differential movements in markups may matter. As used here, relative prices are probably a more reliable indicator of relative technology over longer periods of time.

Figure 8 uses overall TFP and relative prices to derive final-use TFP along the lines of equation (10). I will take the trends in TFP as reflecting technology trends, i.e., the $\widehat{A}_{j}$. In particular, I estimate TFP for durable equipment investment (including consumer durables and inventories); structures investment; and consumption (measured as a residual).

${ }^{21}$.The relative price of inventories in the NIPAs falls relative to consumption, though by less than equipment or consumer durables do.

${ }^{22}$ Much of the recent macro literature uses alternative hedonic deflators from Gordon (1990), but I have not implemented that alternative in the quarterly data. 
All three series fell in the recession and then recovered afterwards, consistent with cyclical fluctuations in utilization. Equipment TFP has continued to rise. Nevertheless, visual inspection suggests that the pace of growth since the mid-1990s has slowed. Structures TFP plunged in the early 2000s but rose during and after the recession. Consumption TFP levels off in the 2000s.

Clearly, the model abstracts from some potentially important aspects. First, production functions and the capital aggregate are equal across sectors. In practice, factor shares are not equal and sectors differ in the intensity of, say, land or inventories. Second, the production and capital-aggregate functions are taken to be Cobb-Douglas. These two assumptions greatly simplify steady-state calculations. In practice, the calculation is best interpreted as a local approximation as long as shares do not change too dramatically. Third, we abstract from the open economy. If, say, the ability to import computer components reduces the relative price of computers, we will take that lower price as indicating faster relative TFP. In the model, faster TFP in producing computers reduces their relative price and encourages capital deepening. In the open economy, the incentive to purchase computers does just depend on the price, whether that price reflects domestic computer TFP or cheaper import prices. Hence, from the point of view of understanding the incentives of computer users to purchase computers, the mapping is appropriate. Fourth, considerable recent literature, including the papers discussed in Section 1D, has focused on intangible capital. Conceptually, this is an additional capital good that the economy produces and uses. However, we do not observe the investment (production) or the stock of intangibles that yields a flow of services (the uses). At different times, the investment versus service flow may dominate measurement. In steady-state, Basu, Fernald, Oulton, and Srinivasan (2003) show that the existence of intangible capital reduces measured TFP relative to true technology, since the service-flow effect dominates. That said, the steady-state mismeasurement is relatively minor. ${ }^{23}$

\footnotetext{
${ }^{23}$ Over shorter periods of time, the mismeasurement may be much larger, as Basu, Fernald, Oulton, and Srinivasan (2003) and Corrado, Hulten, and Sichel (2009) point out.
} 
Table 1 shows that, despite the simplifications in the model, the steady-state implications match the historical data reasonably well. The overall and subsample "misses" are an on the order of few tenths of a percentage point. The multisector model does a somewhat better job of matching the subsample variation; and the model with land does a better job of capturing the magnitude of the pickup in labor productivity after 1997. The main failure of the one-sector model is that it underpredicts capital deepening after 1973. Equivalently, because it assumes the capital-output ratio is constant in steady state, it misses the trend increase in the capital-output ratio in the data.

To use this model to do a steady-state projection of labor productivity in the business sector, we need to take a stand on TFP in the production of investment goods (equipment and structures) as well as in consumption TFP. I consider three scenarios:

- Optimistic: Durables and Consumption TFP grow at post-1997:Q1 rates; Buildings TFP is flat.

- Benchmark: Final-sector TFP grows at post-1986:Q4 rates.

- Pessimistic: Final-use TFP grows at average growth rates since 2003:Q4.

The benchmark is consistent with the view that equipment technology shows some evidence of easing its pace in the 2000s. It downweights the mid-1990s acceleration somewhat by including the 1987-97 period as well as the post-2007 period (when TFP growth was also slower). It also downweights the 2000s declines in structures TFP. The optimistic scenario uses the faster growth period for equipment and consumption, and completely disregards the declines in structures TFP by assuming it is flat going forward.

The benchmark is consistent with the slowdown in labor productivity and TFP growth discussed in Section I, though the underlying trends are stronger than the actual productivity performance since 2003:4. The pessimistic scenario, in contrast, takes seriously that weak performance. Indeed, the pessimistic scenario largely continues the anemic performance of actual productivity since 2003.

Table 2 shows the projections for productivity based on these scenarios. The benchmark has labor productivity growth of about 1.9 percent per year in the business sector. 


\section{B. Projecting Potential Hours Growth and Potential GDP growth}

Returning to equation (5), now that I have a projection for potential labor productivity growth, I combine that with projections for potential labor input and for non-business output from the Congressional Budget Office (CBO, 2012).

The CBO expects relatively slow growth in demographics in the medium- to long-term. In particular, the CBO projects that potential non-farm business hours at the end of the next decade (20202022) will grow at an average of just under 0.5 percent per year. (In recent decades, business hours have risen similarly to non-farm business hours, so for the projections I ignore the differences.) To derive labor input, I also need a projection for labor quality. Jorgenson et al (2011) estimate that by the end of the decade, labor quality will plateau (reflecting the fact that new cohorts have stopped gaining educational attainment relative to retiring cohorts). I therefore assume zero labor-quality growth in the long run. These estimates imply that business output in the benchmark case will grow at the sum of growth in productivity (1.85 percent, with two decimal places $)$ and hours $(0.46$ percent $)=2.3$ percent per year.

The analysis above gives projections for business output. To project GDP, I combine these with the CBO's forecasts for business output. The CBO's estimates that non-business output—which is primarily general government and the service flow from owner-occupied housing-will grow a little under 1.2 percent per year in the longer term. For comparison, non-business output rose at a 2.2 percent pace from 1973 through 2001, and a 1.3 percent pace from 2001-2011. The business sector has averaged 76 percent of GDP since $2001 .^{24}$

Together, the business and non-business projections imply anemic long-run GDP growth of only 2.1 percent per year. By comparison, for the 20 years prior to the Great Recession, GDP growth averaged 3 percent. (Of course, reflecting the effects of the recession itself, growth has been notably slower for the 10year period ending in 2012:2, at only a 1.6 percent annual rate.)

\footnotetext{
${ }^{24}$ Macroeconomic Advisers forecasts that the share will rise to 77 percent by end of the decade.
} 
A long-run projection as low as 2.1 percent appears to be at the low end of recent empirical estimates. For example, Federal Open Market Committee participants present long-run projections for GDP growth four times a year. In April 2012, the median was 2-1/2 percent (with a range of 2.2-3 percent). ${ }^{25}$ Gordon (2010) estimates potential growth of 2.4 percent (for a period corresponding to 2007-2027).

Actual long-run performance could, of course, differ substantially from this benchmark projection. On the one hand, the CBO's demographic assumptions are relatively pessimistic. Macroeconomic Advisers (2012), for example, has non-farm business hours growing at about 1.2 percent per year a decade out, substantially faster than the $\mathrm{CBO}$ assumes. On the other hand, the benchmark productivity assumptions are optimistic relative to the actual post-2003 experience.

\section{Growth of Potential in the Recent Past and Near Future}

With growth-accounting results for the recent period along with the long-run projections, I now turn to estimating potential growth in the near past and future. Conceptually, I follow the approach of the Congressional Budget Office (2001). This method takes a production-function approach, and is "an estimate of the level of GDP attainable when the economy is operating at a high [i.e., normal] rate of resource use" (CBO 2001, page 1).

An appealing, theoretically coherent, alternative comes from the dynamic stochastic general equilibrium (DSGE) literature. That literature typically defines the potential (or natural) rate of output as its value in the absence of nominal rigidities (see, for example, Basu and Fernald (2009) for an extended discussion and references). For example, technology shocks directly affect potential output; but, in addition, these shocks may also induce changes in equilibrium inputs - including the desired intensity with which factors are used - in ways that are ruled out by the CBO method. Other shocks that do not affect the production function itself, such as to the labor-leisure choice or to time preference, can also affect the natural rate of output even in the absence of nominal rigidities.

\footnotetext{
${ }^{25} \mathrm{http}: / /$ www.federalreserve.gov/monetarypolicy/fomcminutes20120425ep.htm.
} 
There are several potential concerns with the DSGE approach in the present context. First, its estimates of potential are model-specific. Different models can interpret the same data quite differently. Second, most DSGE models assume that growth in technology and labor productivity have constant means, which is inconsistent with the evidence presented earlier. A fully-specified regime-switching (or more general) model can be fairly complicated. The need to specify how the underlying trends evolve is an example of the model-specificity of the natural-rate estimates. Nevertheless, Justiniano, Primiceri, and Tambalotti (2011) argue that the output gap in a fairly-standard New Keynesian DSGE models is highly correlated with CBO output gaps (and looks a lot like detrended labor), so the differences between the CBO and DSGE approaches might not be so large.

For these reason, I follow the CBO approach. Specifically, I take the CBO estimate of potential as of the end of 2006 as my starting point. For the period from 2007 through 2014, I "add up" the pieces of potential output growth:

$$
\hat{Y}^{*}=\alpha \hat{K}+(1-\alpha)\left(\hat{H}^{*}+\widehat{L Q}^{*}\right)+\widehat{A}^{*}
$$

As noted earlier, in steady-state, capital growth depends not just on overall technology growth but on its composition. However, for near-term calculations, capital growth is observed (or can be estimated based on near-term forecasts for investment, which depend on factors other than steady-state concerns).

\section{Capital (K)}

Productive capacity in the economy is determined by actual investment, not by the long-run implications of a model. I use actual capital growth through 2012:Q2, and then use Macroeconomic Advisers investment forecasts to project capital growth forward. Figure 9A shows that capital input growth was anemic during the recession. Indeed, it was the weakest in the post-war period. Fluctuations in capital input growth determine the general profile of the potential growth estimate.

\section{- $\operatorname{Hours}\left(\mathrm{H}^{*}\right)$}

I combine CBO (2011) estimates of potential hours with estimates from Daly, Hobijn, Şahin, and Valletta (2012) on changes in the NAIRU. These changes reflect matching and other labor market frictions that reduce frictionless "full employment." Hence, I assume changes in the Daly et al. NAIRU (which are not adjusted for extended unemployment benefits) affect potential hours worked one-for-one (e.g., a 1 percentage point rise in the NAIRU reduces potential hours by 1 percent). From 2008 through 2010, the NAIRU increased from 4.8 to 6.0 percent, thereby reducing 
potential labor input by a total of 1.2 percentage points. In 2013 and 2014, I assume a falling NAIRU increases potential labor input by 0.4 percentage points. ${ }^{26}$

\section{- Labor Quality (LQ*)}

Potential labor quality rises at its actual rate in 2007, but from 2008 through 2014 rises at the potential rate estimated by Jorgenson et al (2011). (Actual labor quality rose more quickly than this from 2008-2011, as low-skilled workers disproportionately lost employment.) The average growth rate of potential labor quality from $2007-2014$ is 0.20 percent.

\section{- Technology $\left(\widehat{A}^{*}\right)$}

I assume that $\widehat{A}^{*}$ rises at its assumed long-run benchmark rate (from Table 2) of 0.9 percent per year.

Together, these assumptions imply the "Fernald" path of potential shown in Figure 9B. For comparison, the figure shows the August 2012 CBO projection, which is qualitatively similar but somewhat more optimistic. It also shows what the CBO was projecting in mid-2007—prior to the Great Recession. Relative to a pre-crisis projection, potential output appears notably lower today. To summarize, the two main reasons for reducing potential are

(i) reduced underlying TFP growth, which wasn't apparent in 2007; and

(ii) reduced growth in capacity during the crisis.

Actual real GDP as of the end of 2011 was more than 10 percent below the 2007 CBO projection. Despite the large downward revision in potential since 2007, potential remains well above actual output. The "Fernald" estimate here decomposes about half of the shortfall relative to the 2007 trend into a downgrade of potential, and about half into an output gap (output below potential).

Once transitory/business-cycle dynamics play out, the neoclassical model would imply that the marginal product of capital will be high relative to steady state, encouraging capital formation. Hence, potential growth will temporarily "overshoot" on its return to steady-state. In other words, some of the reduction in potential is simply a consequence of the recession itself.

\footnotetext{
${ }^{26}$ See Daly, Hobijn, Şahin, and Valletta (2012) for a discussion of the some of the methodological issues underlying this measure.
} 
The key factors underlying the gap appear to be on the labor side. Hours worked fell dramatically during the recession and have yet to recover. In terms of unemployment, the current rate of more than 8 percent is well above the estimated NAIRU in Daly, Hobijn, Şahin, and Valletta (2012) of around 6 percent. ${ }^{27}$ In other words, there is a sizeable gap between actual and potential labor input.

The next section considers sensitivity to the assumptions about technology as well as about scrappage of capital. Another risk to the near-term projections for potential output is that persistent weakness in aggregate demand could corrode supply. For example, workers could lose skills and, potentially, drop out of the labor force permanently. This risk highlights that persistently weak demand could lead potential to be even weaker than anticipated here.

Finally, consider the period prior to the crisis, say in 2006 , where I simply used the CBOs estimates. The CBO estimates that output was only slightly above potential at that time. The methodology in this section implicitly estimates the output gap in 2012 by projecting the CBO's gap from 2006 using actual GDP growth and an estimate of potential growth. Therefore, if actual output were, in fact, further above potential prior to the crisis, then today's output gap would be reduced.

There are clear reasons to believe that aspects of the economy were unsustainable in the mid-2000s. However, these do not necessarily imply that the level of output was unsustainable. With hindsight, one could easily argue that in the mid-2000s, there were two related problems: (i) the economy was producing the "wrong" stuff (too many houses), and (ii) economic agents were buying the wrong stuff (e.g., using home equity as an ATM to finance too-much consumption). Both problems are consistent with the CBO estimates. Conceptually, the economy built capital goods (houses) that turned out not to be productive. In the CBO estimates, that construction was part of actual and potential output when it was built. Later on, when the housing did not provide a service flow, then both actual and potential non-business output (the services of owner-occupied housing) has been lower than one would have anticipated in 2007. That is one reason for

\footnotetext{
${ }^{27}$ The effects of extended unemployment benefits probably raise the "effective NAIRU" slightly above 6 percent. However, with the end of the program and residents of some states no longer qualifying, the effects appear relatively small at this point.
} 
the downward revision in potential (though not the primary reason). In terms of buying too much consumption, the implied impetus to aggregate demand is consistent with output being above potential prior to the crisis. But much of the consumption was imported, and "paid for" by borrowing from abroad, not by overproducing domestically.

\section{Robustness to Mismeasurement of Capital and Technology}

Could there have been unmeasured declines in capital or technology leading to a much greater decline in potential output than implied by the limited structural drop in hours? After all, both capital and technology could easily be mismeasured. Both sources of mismeasurement affect actual measured TFP, which can be used to get an estimate that is robust to these concerns. The reason is that true capital and technology affect actual output — and the measured Solow residual—as well as potential. The cost of using actual TFP, of course, is that it puts any cyclical variation in measured TFP into potential. ${ }^{28}$

Regarding capital, a potential concern is unobserved scrappage rates. The resulting bias could go either way. On the one hand, if the economy has too much auto capacity, or too many back hoes, this capital could have been scrapped. On the other hand, firms may have deferred scrappage and continued to use old but still serviceable capital rather than replacing it. ${ }^{29}$

Measured TFP growth bounds the possible bias. Since TFP is measured as a residual, it inherently incorporates the effects on output from actual changes in capital — whether measured or unmeasured -as well as broad economic efficiency. Specifically, let:

$$
\begin{aligned}
& \hat{K}^{\text {Measured }}=\hat{K}+\kappa \\
& \widehat{A}^{\text {Measured }}=\widehat{A}^{*}+\tau
\end{aligned}
$$

Measured growth in capital, which we use in our near-term estimates, overstates true growth $\hat{K}$ by $\kappa$. We also assumed a smooth benchmark path for underlying technology, $\widehat{A}^{\text {Measured }}$, which may overstate

\footnotetext{
${ }^{28}$ In principle, using utilization-adjusted TFP controls for this cyclical variation. However, it is dependent on the specific model of utilization and, in the case of the Fernald measure, there could be end-point issues involved with removing trends from the hours data.

${ }^{29}$ I thank Nick Oulton for this observation.
} 
true technology by (time-varying) $\tau$. Suppose we estimate potential growth, but with these two sources of measurement error. This measured potential, $\hat{Y}^{* \text {,Measured }}$, estimated using (5), overstates true potential growth by:

$$
\hat{Y}^{* \text { Measured }}-\hat{Y}^{*}=\alpha \kappa+\tau
$$

If we are overoptimistic about growth in capital input or technology, then we overestimate potential growth as well.

We can use measured TFP, or utilization-adjusted TFP, to obtain a reasonable bound on the magnitude of the mismeasurement. Specifically, suppose (as in equation (3)) that $\widehat{T F P}=\widehat{A^{*}}+\widehat{U t i l}$, where $\widehat{U t i l}$ is the effect of growth in the workweek of capital and labor effort. Measured TFP growth, with error in capital, is

$$
\begin{aligned}
\widehat{T F P}^{\text {Measured }} & =\hat{Y}-\alpha \hat{K}^{\text {Measured }}-(1-\alpha)(\hat{H}+\widehat{L Q}) \\
& =\hat{Y}-\alpha \hat{K}-(1-\alpha)(\hat{H}+\widehat{L Q})+\alpha\left(\hat{K}-\hat{K}^{\text {Measured }}\right) \\
& =-\alpha \kappa+\widehat{A}^{*}+\widehat{U t i l}
\end{aligned}
$$

Potential, using not only mismeasured capital growth but also $\widehat{T F P}^{\text {Measured }}$ in place of $\widehat{A}^{\text {Measured }}$, is

$$
\begin{aligned}
\hat{Y}^{*}, T F P & =\alpha(\hat{K}+\kappa)+(1-\alpha)\left(\hat{H}^{*}+\widehat{L Q}^{*}\right)+-\alpha \kappa+\widehat{\text { Tech }}+\widehat{\text { Util }} \\
& =\hat{Y}^{*}+\widehat{\text { Util }} .
\end{aligned}
$$

If potential is estimated with actual TFP growth, it still, inappropriately, contains error arising from any cyclical mismeasurement of technology that is captured by $\widehat{U t i l}$. However, estimated potential is not affected by measurement error in growth in capital, $\kappa$, or in underlying technology, $\tau$. The reason is that TFP is measured as a residual. Hence, ceteris paribus, anything that affects actual output affects measured TFP as well. And actual output depends on true capital and technology.

When we redo the estimates from the previous section, using measured TFP or the Fernald measure of utilization-adjusted TFP, we do get a substantially lower estimate of potential output. From 2006:Q4 through 2012:Q2, actual (as well as the Fernald measure of utilization-adjusted) TFP grew an average annual 
pace of under 0.1 percent. Using these numbers reduces the 2011:4 level of potential output by about 3 percentage points. This is certainly a sizeable reduction in the gap. Nevertheless, it still leaves an output gap of about 2-1/4 percent, a bit under one half as large as in the benchmark case.

I do not take this alternative as my benchmark because, as a measure of technology, TFP is subject to various sources of cyclical measurement error which are likely to be particularly pronounced during a business cycle as deep and disruptive as the recent one. Even the utilization-adjusted measure may not capture all of those effects. Instead, I interpret these results as bounding the effects of capital or technology measurement error. Although the gap is substantially smaller with actual TFP, there is still a gap.

\section{Conclusions}

In assessing recent dynamics of labor productivity and potential output, this paper makes four points. First, after accelerating in the mid-1990s, labor productivity growth slowed again after the early to mid 2000s. This slowdown preceded the Great Recession and is consistent with reduced investment in intangible organizational capital associated with information technology. There is little evidence so far that underlying productivity trends have substantially changed further during the recession and recovery.

Second, in contrast to informal commentary, labor and total-factor productivity performance during the Great Recession and early in the subsequent recovery was largely in line with previous recession experience. Peak to trough, total factor productivity (TFP) saw the sharpest downturn in the post-war period, consistent with labor and capital hoarding. Labor productivity did not decline as much, reflecting a surge in capital deepening during the recession (since labor fell much more than capital) and labor quality (as lowskilled workers disproportionately lost their jobs). During the recovery, as measures of factor utilization fairly quickly returned to normal, TFP and labor productivity returned roughly to their mid-2000s trend.

Third, using a multi-sector neoclassical growth framework, steady-state potential output is likely to rise at about a 2.1 percent pace. This appears to be at the low end of recent estimates. Finally, during the recession and recovery, potential output growth was well below that pace-reflecting not only the slower 
underlying growth in technology but also the sharply reduced capital growth during the recession and early recovery. Despite this substantially slower pace of potential, actual output is even lower. About half of the shortfall relative to pre-recession trends is a revision to potential, and half is an output gap.

An open issue remains whether the Great Recession itself might leave a permanent mark on potential. The slow underlying technology trends appear to pre-date the Great Recession itself. And to the extent the reduced recent pace of physical capital formation is cyclical, it should rebound when the economy finally recovers. Nevertheless, one can tell stories in which the recession reduces investment in innovation that permanent affects the path of output (see, e.g,. Barlevy, 2004). And there could also be permanent labor market scars, to the extent unemployed workers lose skills or labor-market attachment. These forces could become more apparent over time. But the estimates in this paper do suggest that future assessments will need to be careful not to conflate the (unrecognized) pre-crisis slowdown in underlying technology with permanent crisis effects. 


\section{Bibliography}

Aaronson, Daniel and Daniel G. Sullivan (2001). "Growth in worker quality." Federal Reserve Bank of Chicago Economic Perspectives, , Vol. 25, 4th Quarter.

Barlevy, Gadi (2004). "The Cost of Business Cycles under Endogenous Growth." American Economic Review, 94(4), p964-90.

Basu and Fernald (2002). "Aggregate Productivity and Aggregate Technology.” European Economic Review.

Basu, Susanto and John Fernald (2009). "What Do We Know and Not Know About Potential Output?" St. Louis Fed Review.

Basu, Susanto, John Fernald, Jonas Fisher, and Miles Kimball (2010). “Sector-Specific Technical Change.” Manuscript, Federal Reserve Bank of San Francisco.

Basu, Susanto, John Fernald, and Miles Kimball (2006). “Are Technology Improvements Contractionary?” American Economic Review.

Basu, Susanto, John Fernald, Nicholas Oulton, and Sally Srinivasan (2003). The Case of the Missing Productivity Growth: Or, Does Information Technology Explain Why Productivity Accelerated in the United States but Not the United Kingdom? NBER Macroeconomics Annual, 2003.

Bresnahan, T. F., and M. Trajtenberg. (1995). General-purpose technologies:"Engines of growth"? Journal of Econometrics 65(Special Issue, January): 83-108.

Brynjolfsson, E., and L. M. Hitt. (2000). "Beyond computation: Information technology, organizational transformation and business performance." Journal of Economic Perspectives 14(4):23-48.

Congressional Budget Office (2001). "CBO's Method for Estimating Potential Output: An Update.” The Congress of the United States, Congressional Budget Office.

http://www.cbo.gov/sites/default/files/cbofiles/ftpdocs/30xx/doc3020/potentialoutput.pdf.

Congressional Budget Office (2011). "The Budget and Economic Outlook: An Update.” August. The Congress of the United States, Congressional Budget Office.

http://www.cbo.gov/sites/default/files/cbofiles/attachments/08-24-BudgetEconUpdate.pdf.

Congressional Budget Office (2012). "An Update to the Budget and Economic Outlook: Fiscal Years 2012 to 2022." The Congress of the United States, Congressional Budget Office. August 2012. http://www.cbo.gov/publication/43539

Corrado, Carol, Charles Hulten, and Daniel Sichel (2006). "Intangible Capital and Economic Growth." Review of Income and Wealth, Series 55, No. 3, September 2009

Cummins, Jason G. and Giovanni L. Violante (2002). "Investment-Specific Technical Change in the US (1947-2000): Measurement and Macroeconomic Consequences," Review of Economic Dynamics, vol. 5(2), pages 243-284, April.

Daly, Mary C., Bart Hobijn, Ayşegül Şahin and Robert G. Valletta (2012). 2012. "A Search and Matching Approach to Labor Markets: Did the Natural Rate of Unemployment Rise?" Journal of Economic Perspectives, 26(3): 3-26.

Dean , Edwin R. and Michael J. Harper (2001). “The BLS Productivity Measurement Program.” In New Developments in Productivity Analysis, Charles R. Hulten, Edwin R. Dean and Michael J. Harper, editors. University of Chicago Press. 
Diewert, W.E. (1976), "Exact and Superlative Index Numbers", Journal of Econometrics 4, 114-145.

Eisfeldt, Andrea and Adriano Rampini (2006). "Capital reallocation and liquidity." Journal of Monetary Economics 53: 369-399.

Fernald, John G. (2007). "Trend Breaks and Contractionary Technology Improvements." Journal of Monetary Economics.

Fernald, John G. (2012a). "A Quarterly Utilization-Adjusted Series on Total Factor Productivity." Manuscript, http://www.frbsf.org/economics/economists/jfernald.html. Data supplement at http://www.frbsf.org/economics/economists/jfernald/quarterly_tfp.xls.

Fleck, Susan (2011). "Measuring State-level Productivity in the Private Industry Sector." Manuscript, Bureau of Labor Statistics, December 2011.

Francis, Neville and Valerie Ramey (2009). "Measures of Per Capita Hours and Their Implications for the Technology-Hours Debate." Journal of Money, Credit, and Banking, Sept. 2009

Galí, Jordi \& Thijs van Rens (2010). "The Vanishing Procyclicality of Labor Productivity." IZA Discussion Papers 5099, Institute for the Study of Labor (IZA).

Gali, Jordi, Frank Smets, and Rafael Wouters (2012). "Slow Recoveries: A Structural Interpretation.” Manuscript, CREI.

Gordon, Robert J. (1990). The Measurement of Durable Goods Prices, Chicago: University of Chicago Press.

Gordon, Robert J. (2010). "Revisiting U.S. Productivity Growth over the Past Century with a View of the Future." NBER Working Paper 15834, March.

Gordon, Robert J. (2011a). “Okun's Law and Productivity Innovations .” American Economic Review Papers and Proceedings, vol. 100, no. 2, pp. 11-15.

Gordon, Robert J. (2011b). "The Evolution of Okun's Law and of Cyclical Productivity Fluctuations in the United States and in the EU-15." For Presentation at EES/IAB Workshop,Labor Market Institutions and the Macroeconomy Nuremberg, June 17-18, 2011.

Greenwood, Jeremy, Zvi Hercowitz, and Per Krusell (1997). "Long-Run Implications of InvestmentSpecific Technological Change," American Economic Review, vol. 87(3), pages 342-62.

Greenwood, Jeremy and Mehmet Yorukoglu (1997). "1974," Carnegie-Rochester Conference Series on Public Policy, Elsevier, vol. 46(1), pages 49-95, June.

Hobijn, Bart and Alistair McKay (2007). "Spurious Investment Prices.” Unpublished manuscript, Federal Reserve Bank of San Francisco.

Hobijn, Bart and Boyan Jovanovic. (2001). "The information-technology revolution and the stock market: Evidence." American Economic Review 91 (December): 1203-1220.

Helpman, E., ed. (1998). General Purpose Technologies and Economic Growth. Cambridge, MA: MIT Press.

Hulten, Charles R. (1978). "Growth Accounting with Intermediate Inputs," Review of Economic Studies, Vol. 45,No. 3, pp. 511-518.

Jorgenson, Dale W. (2000). "Raising the Speed Limit: U.S. Economic Growth in the Information Age," Brookings Papers on Economic Activity, No. 1, 2000 (with K. J. Stiroh), pp. 125-212.

Jorgenson, Dale W., Richard Goettle, Mun Ho, and Peter Wilcoxen (2011). "Energy, the Environment and U.S. Economic Growth," forthcoming in Dixon and Jorgenson (eds) "Handbook of Computable General Equilibrium Modeling" 
Jorgenson, Dale W., Frank M. Gollop, and Barbara M. Fraumeni (1987). Productivity and U.S. Economic Growth. Cambridge, Harvard University Press.

Justiniano, Alejandro, Giorgio E. Primiceri, and Andrea Tambalotti (2011). "Is There a Trade-off Between Inflation and Output Stabilization?" NBER Working Papers 17071, National Bureau of Economic Research, Inc.

Kahn, James and Robert Rich (2011). "The Productivity Slowdown Reaffirmed." http://libertystreeteconomics.newyorkfed.org/2011/09/the-productivity-slowdown-reaffirmed.html. September 28, 2011.

Macroeconomic Advisers (2012). Long-Run Database. Forecast dated April 20, 2012. Accessed via Haver Analytics.

Nalewaik, Jeremy J. (2010). "The Income- and Expenditure-Side Measures of Output Growth," Brookings Papers on Economic Activity, vol. 1, pp. 71-106.

Oliner, Stephen D. and Daniel E. Sichel, 2000. "The Resurgence of Growth in the Late 1990s: Is Information Technology the Story?" Journal of Economic Perspectives, vol. 14(4), pages 3-22, Fall.

Oliner, Stephen D., Daniel E. Sichel, and Kevin Stiroh (2007). "Explaining a Productive Decade." Brookings Papers on Economic Activity.

Whelan, Karl (2003). "A Two-Sector Approach to Modeling U.S. NIPA Data," Journal of Money, Credit and Banking, vol. 35(4), pages 627-56, August. 


\section{Appendix A: Fernald (2012) Quarterly Growth-Accounting Data}

These data are available at http://www.frbsf.org/economics/economists/jfernald/quarterly tfp.xls. They include quarterly growth-accounting measures for the business-sector, including output, hours worked, labor quality (or composition), capital input, and total factor productivity from 1947:Q2 on. In addition, they include a measure of factor utilization that follows Basu, Fernald, and Kimball. They are typically updated one to two months after the end of the quarter (for example, data through 2011:Q4 were posted on February 2, 2012, following the release of BLS Productivity and Cost data for the fourth quarter). Once aggregated to an annual frequency, they are fairly close to the annual BLS multifactor productivity estimates, although there are some differences in coverage and implementation. ${ }^{30}$ The data are described in greater detail in Fernald (2012).

Key data sources for estimating (unadjusted) quarterly TFP for the U.S. business sector are:

(i) Business output: As recommended by Nalewaik (2011), a geometric average of output as measured from the income and expenditures sides. The expenditure (or product) side is reported in NIPA tables 1.3.5 and 1.3.6 (gross value added by sector). Nominal business income (the counterpart of gross domestic income) is GDI less nominal non-business output from table 1.3.5. Real business income uses the expenditure-side deflators.

(ii) Hours: From the quarterly BLS productivity and cost release.

(iii) Capital input: Weighted growth in 13 types of disaggregated quarterly capital. Weights are estimated factor payments (which, in turn, use estimated user costs). The quarterly national income and product accounts (produced by the Bureau of Economic Analysis, BEA) provide quarterly investment data for 6 types of non-residential equipment and software; and for 5 types of non-residential structures. I use these data to create perpetual-inventory series on (end of previous quarter, i.e., beginning of current quarter) capital stocks by different type of asset. In addition, I use quarterly NIPA data on inventory stocks and interpolate/extrapolate the annual BLS estimates of land input. Note that the data also allow me to calculate subaggregates, such as equipment and software capital, or structures capital.

(iv) Factor shares: I interpolate and, where necessary, extrapolate the annual data on factor shares, $\alpha$ and $(1-\alpha)$, from the BLS multifactor productivity database.

(v) Labor composition: From 1979:1 on, I use estimates that follow Aaronson and Sullivan (2001), as updated by Bart Hobijn and Joyce Kwok. Prior to 1979, I interpolate and extrapolate annual data from BLS multifactor productivity data.

(vi) Investment versus consumption technology: To decompose aggregate TFP along final demand lines, I create three Tornquist price indices from NIPA data. The first is the price of "equipment," defined as equipment, software, and consumer durables. The second is the price of structures, defined as residential and non-residential structures. The third is the price of non-durable "consumption," defined as everything else-i.e., the price of business output less equipment and structures. I assume the relative price of equipment investment corresponds, quarter-by-quarter, to TFP in consumption relative to equipment investment.

\footnotetext{
${ }^{30}$ To name six minor differences: (i) BLS covers private business, Fernald covers total business. (ii) BLS uses expenditure-side measures of output, whereas Fernald combines income and expenditure-side measures of output. (iii) BLS assumes hyperbolic (rather than geometric) depreciation for capital. (iv) BLS uses the more disaggregated investment data available at an annual frequency. (v) Fernald does not include rental residential capital. (vi) There are slightly different methodologies for estimating labor quality. Some of these differences reflect what can be done quarterly versus annually. For a review of the methodology and history of the BLS measures, see Dean and Harper (2001).
} 
(This measure of relative TFP is not, of course, necessarily equal to technology change period by period.)

To estimate a quarterly series on utilization, the key data source is the following:

(vii) Hours-per-worker $\left(H^{i} / N^{i}\right)$ by industry from the monthly employment report of the BLS. These are used to estimate a series on industry utilization $\Delta \ln U_{i}=\beta_{i} \Delta \ln \left(H^{i} / N^{i}\right)$, where $\beta_{i}$ is a coefficient estimated by Basu, Fernald, and Kimball (BFK, 2006). I then calculate an aggregate utilization adjustment as $\Delta \ln U=\sum_{i} w_{i} \Delta \ln U_{i}$, where $w_{i}$ is the industry weight from BFK (taken as the average value over the full sample).

The resulting utilization-adjusted series differs conceptually from the BFK purified technology series along several dimensions. BFK use detailed industry data to construct estimates of industry technology change that control for variable factor utilization and deviations from constant returns and perfect competition. They then aggregate these residuals to estimate aggregate technology change. Thus, they do not assume the existence of a constant-returns aggregate production function. The industry data needed to undertake the BFK estimates are available only annually, not quarterly. As a result, the quarterly series estimated here does not control for deviations from constant returns and perfect competition. ${ }^{31}$

\footnotetext{
${ }^{31}$ The output data also differ, both in vintage and data source, from the annual data used by BFK.
} 


\section{Appendix B: Projecting Labor Productivity in Neoclassical Growth Models}

This appendix discusses how to estimate steady-state labor productivity growth from estimates of underlying technology growth. It uses a neoclassical model to derive the implications for capital deepening. Section A summarizes the familiar one-sector Solow model. Section B develops a two-sector Solow model, which highlights the key takeaways and intuition for the multi-sector model. Section C derives the (straightforward, but somewhat tedious) extension to the case with consumer durables, land, and inventories.

A few equations will be useful as preliminaries. Let hats over a variable represent log changes. As an identity, output growth, $\hat{Y}$, is labor-productivity growth plus growth in hours worked, $\hat{H}$ :

$$
\hat{Y}=(\hat{Y}-\hat{H})+\hat{H} \text {. }
$$

We focus here on full-employment labor productivity, so we abstract from utilization.

Growth in total factor productivity, or the Solow residual, is defined as

$$
\widehat{T F P}=\hat{Y}-\alpha \hat{K}-(1-\alpha) \hat{N}
$$

where $\alpha$ is capital's share of income and (1- $\alpha$ ) is labor's share. Defining $\hat{N} \equiv \hat{H}+\widehat{L Q}$, where $\widehat{L Q}$ is labor "quality" (composition) growth ${ }^{32}$, output per hour growth is:

$$
(\hat{Y}-\hat{H})=\widehat{T F P}+\alpha(\hat{K}-\hat{N})+\widehat{L Q} \text {. }
$$

Growth in output per hour worked reflects TFP growth; the contribution of capital deepening, defined as $\alpha(\hat{K}-\hat{N})$; and increases in labor quality. Economic models suggest mappings between fundamentals and the terms in this identity.

It is sometimes useful to rearrange (12) to yield:

$$
(\hat{Y}-\hat{H})=\widehat{T F P} /(1-\alpha)+\alpha(\hat{K}-\hat{Y})+\widehat{L Q}
$$

We now show how a one-sector and two-sector model map to these equations. Then we allow for a third sector, and for inventories, and land.

\section{A. The one-sector Solow model}

The Solow model provides a particularly simple model that maps exogenous growth in technological progress and the labor force to endogenous capital deepening.

Consider an aggregate production function $Y=K^{\alpha}(A N)^{1-\alpha}$, where labor-augmenting technology $A$ grows at rate $g$, and labor input $N$ (which captures both raw hours $H$ and labor quality $L Q$-henceforth, I do not generally differentiate between the two) grows at rate $n$. Expressing all variables in terms of "effective labor" $A N$ yields:

$$
y=k^{\alpha}, \text { where } y=Y / A N \text { and } k=K / A N \text {. }
$$

${ }^{32}$ In the BLS multifactor productivity dataset, from 1948 through 2010, hours grew 0.8 percent per year, and labor quality/composition grew 0.3 percent per year. Hence, more than a quarter of labor input growth in the MFP data reflects labor quality. Labor quality, in turn, reflects the mix of hours across workers with different levels of education, experience, and so forth. For the purposes of this discussion, where we're so far focused on definitions, suppose there were $J$ types of workers with factor shares of income $\beta_{j}$, where $\sum_{j} \beta_{j}=(1-\alpha)$. Then a reasonable definition of TFP would be $\widehat{T F P}=\hat{Y}-\alpha \hat{K}-\sum_{j} \beta_{j} \hat{H}_{j}$. Growth accounting as done by the Bureau of Labor Statistics or Jorgenson defines $\hat{L}=\sum_{j} \beta_{j} \hat{H}_{j} /(1-\alpha), \hat{H}=d \ln \left(\sum_{j} H_{j}\right)$, and $\widehat{L Q} \equiv \hat{L}-\hat{H}$. 
Capital accumulation takes place according to the perpetual-inventory formula, $\dot{K}=I-\delta K$. Let $s$ is the saving rate, so that $s y$ is investment per effective worker. In steady-state:

$$
s y=(n+\delta+g) k
$$

Because of diminishing returns to capital, the economy converges to a steady state where $y$ and $k$ are constant. At that point, investment per effective worker is just enough to offset the effects of depreciation, population growth, and technological change on capital per effective worker. In steady state, the unscaled levels of $Y$ and $K$ grow at the same rate $g+n$; capital-deepening, $K / N$, grows at rate $g$. Labor productivity $Y / N$, i.e., output per unit of labor input, also grows at rate $g$.

From the production function, measured TFP growth is related to labor-augmenting technology growth by:

$$
\widehat{T F P}=\hat{Y}-\alpha \hat{K}-(1-\alpha) \hat{N}=(1-\alpha) g .
$$

The model maps directly to equations (13) and (14) above. In steady state, $\hat{K}=\hat{Y}$, and, as in equation (14), output per unit of labor grows at $g=\widehat{T F P} /(1-\alpha)$. Alternatively, in terms of equation (13), the endogenous contribution of capital deepening to labor-productivity growth is $\alpha(\hat{K}-\hat{N})=\alpha g=\alpha \cdot \widehat{T F P} /(1-\alpha)$. Thus, we can write growth in output per hour in a form that corresponds closely with the two-sector version below:

$$
\hat{Y}-n=\widehat{T F P}+\alpha \cdot \widehat{T F P} /(1-\alpha)
$$

Growth in output per unit of labor depends on standard TFP growth and induced capital deepening.

\section{B. The two-sector Solow model}

In contrast to the predictions of the one-sector model, the capital-output ratio in the data rises steadily after the early 1970 s. The literature on investment specific technical change suggests a straightforward fix for this model failure: Capital-deepening doesn't depend on overall TFP, but on TFP in the investment sector. A key motivation for this literature is the declining price of business investment goods, especially equipment and software, relative to the price of other goods (such as consumption). The most natural interpretation of the declining relative price is faster technical change in producing investment goods (especially high-tech equipment). ${ }^{33}$

Consider a simple two-sector Solow-type model, where $s$ is the share of nominal output that is invested each period. ${ }^{34}$ One sector produces investment goods that are used to create capital; the other produces consumption goods. The two sectors use the same Cobb-Douglas production function, but with potentially different technology levels:

$$
\begin{aligned}
& I=K_{I}^{\alpha}\left(A_{I} N_{I}\right)^{1-\alpha} \\
& C=Q K_{C}^{\alpha}\left(A_{I} N_{C}\right)^{1-\alpha}
\end{aligned}
$$

In the consumption equation, we have implicitly defined labor-augmenting technological change as $A_{C}=Q^{1 /(1-\alpha)} A_{I}$ in order to decompose consumption technology into the product of investment technology $A_{I}$ and a "consumption specific" piece, $Q^{1 /(1-\alpha)}$. Let investment technology $A_{I}$ grow at rate $g_{I}$ and the consumption-specific piece $Q$ grow at rate $q$. Perfect competition and cost-minimization imply that price

${ }^{33}$ On the growth accounting side, see, for example, Jorgenson (2001) or Oliner and Sichel (2000); see also Greenwood, Hercowitz, and Krusell (1997).

${ }^{34}$ This model is a fixed-saving rate version of the two-sector neoclassical growth model in Whelan (2003) and is isomorphic to the one in Greenwood, Hercowitz, and Krusell (1997). Greenwood et al. choose a different normalization of the two technology shocks in their model. 
equals marginal cost. If the sectors face the same factor prices (and the same rate of indirect business taxes), then relative marginal costs depend solely on relative technology:

$$
\frac{P_{I}}{P_{C}}=\frac{M C^{C}}{M C^{I}}=Q
$$

The sectors also choose to produce with the same capital-labor ratios, implying that $K_{I} / A_{I} N_{I}=K_{C} / A_{I} N_{C}=K / A_{I} N$. We can then write the production functions as:

$$
\begin{aligned}
& I=A_{I} N_{I}\left(K / A_{I} N\right)^{\alpha} \\
& C=Q A_{I} N_{C}\left(K / A_{I} N\right)^{\alpha}
\end{aligned}
$$

We can now write the economy's budget constraint in a simple manner:

$$
\begin{gathered}
Y^{\text {Inv. Units }} \equiv[I+C / Q]=A_{I}\left(N_{I}+N_{C}\right)\left(K / A_{I} N\right)^{\alpha} \text {, or } \\
y^{\text {Inv. Units }}=k^{\alpha} \text {, where } y^{\text {Inv. Units }}=Y^{\text {Inv. Units }} / A_{I} N \text { and } k=K / A_{I} N .
\end{gathered}
$$

Output here is expressed in investment units, and "effective labor" is in terms of technology in the investment sector. The economy mechanically invests a share $s$ of nominal investment, which implies that investment per effective unit of labor is $i=s \cdot y^{\text {Inv. Units }} .^{35}$

Capital accumulation turns out to take the same form as in the one-sector model, except that it is only growth in investment technology, $g_{I}$, that matters. In particular, in steady state: ${ }^{36}$

$$
s y^{\text {Inv. Units }}=\left(n+\delta+g_{I}\right) k
$$

The production function (19) and capital-accumulation equation (20) correspond exactly to their one-sector counterparts. Hence, the dynamics of capital in this model reflect technology in the investment sector alone. In steady state, capital per unit of labor, $K / L$, grows at rate $g_{I}$, so the contribution of capital deepening to labor-productivity growth from equation (13) is

$$
\alpha(\hat{K}-\hat{N})=\alpha g_{I}=\alpha \cdot \widehat{T F P}_{I} /(1-\alpha)
$$

Consumption technology in this model is "neutral," in that it does not affect investment or capital accumulation; the same result generally carries over to the Ramsey version of this model, with or without variable labor supply. (Basu, Fernald, Fisher, and Kimball, 2011, discuss the idea of consumptiontechnology neutrality in greater detail.)

In the data, output is not expressed in investment units but as chained units. Chain GDP growth is defined as share-weighted growth in final expenditure categories:

$$
\hat{Y}=s \hat{I}+(1-s) \hat{C}
$$

From equation (18), in steady state, when $k=K / A_{I} N$ is constant, $\hat{I}$ grows at rate $\left(n+g_{I}\right)$ and $\hat{C}$ grows at rate $\left(n+g_{I}+\hat{q}\right)$. Hence, $\hat{Y}=n+g_{I}+(1-s) \hat{q}$ and the capital-output ratio grows at $\hat{K}-\hat{Y}=\left(n+g_{I}\right)-\left(n+g_{I}+(1-s) \hat{q}\right)=-(1-s) \hat{q} \quad$ Since consumption TFP growth is generally lower than investment TFP growth, $\hat{q}$ is negative in the data, and the model predicts that the measured capital-output ratio is increasing. Note that overall TFP growth in chain-units is:

${ }^{35} s \cdot y^{\text {Inv. Units }}=\left[P_{I} I /\left(P_{I} I+P_{C} C\right)\right]\left[\left(I+P_{C} C / P_{I}\right) / A_{I} N\right]=I / A_{I} N$

${ }^{36}$ The time-derivative $\dot{k}=d / d t(K / A N)=(K / A N)\left(\dot{K} / K-n-g_{I}\right)$. Substituting the capital accumulation equation, $\dot{K} / K=I / K-\delta$, yields $\dot{k}=i-\left(n+g_{I}+\delta\right) k$. In steady-state, $\dot{k}=0$. Substituting for $i$ yields (20). 


$$
\begin{aligned}
\widehat{T F P} & =\hat{Y}-\alpha \hat{K}-(1-\alpha) \hat{N} \\
& =n+g_{I}+(1-s) \hat{q}-\alpha\left(n+g_{I}\right)-(1-\alpha) n \\
& =(1-\alpha) g_{I}+(1-s) \hat{q}
\end{aligned}
$$

Hence, using (21) and (22), growth in output per unit of labor can be written:

$$
\hat{Y}-n=g_{I}+(1-s) \hat{q}=\widehat{T F P}+\alpha \frac{\widehat{T F P}}{(1-\alpha)}
$$

This equation takes the same form as (17), except that capital deepening is solely in terms of investment-sector TFP growth.

To take this model to the data, we need to decompose aggregate TFP growth (calculated from chained output) into its consumption and investment components. Given the conditions so far, the following two equations hold:

$$
\begin{aligned}
& \widehat{T F P}=s \cdot \widehat{T F P}_{I}+(1-s) \widehat{T F P}_{C} \\
& \widehat{P}_{C}-\widehat{P}_{I}=\widehat{T F P}_{C}-\widehat{T F P}_{I}
\end{aligned}
$$

Prices, investment shares, and aggregate TFP are known. Hence, these are two equations in two unknowns- $\widehat{T F P}_{I}$ and $\widehat{T F P}_{C}{ }^{37}$

\section{C. $\quad$ Three sector model}

In practice, there are multiple types of capital. The most important distinction is between fastgrowing equipment and more slowly growing structures. ${ }^{38}$ The argument would naturally extend to more types of capital, as well. Suppose that there's a Durable sector that produces equipment, a Building sector that produces structure, and a Consumption sector: ${ }^{39}$

$$
\begin{aligned}
& D=\left(K_{D}\right)^{\alpha}\left(A N_{E}\right)^{1-\alpha} \\
& B=Q_{B}\left(K_{B}\right)^{\alpha}\left(A N_{B}\right)^{1-\alpha} \\
& C=Q_{C}\left(K_{C}\right)^{\alpha}\left(A N_{C}\right)^{1-\alpha}
\end{aligned}
$$

Some durable goods are consumed as durables. Other durable goods are invested and become equipment capital according to the usual perpetual inventory equation. Similarly, new buildings become gross investment in structures. All three sectors use the same capital aggregate, which uses equipment $E$ and structures $S$.

$$
K=E^{c_{E}} S^{1-c_{E}}=K_{D}+K_{B}+K_{C}
$$

${ }^{37}$ The calculations in the text use the official price deflators from the national accounts. Gordon (1990) argues that many equipment deflators are not sufficiently adjusted for quality improvements over time. Much of the macroeconomic literature since then has used the Gordon deflators (possibly extrapolated, as in Cummins and Violante, 2002). Of course, as Whelan (2003) points out, much of the discussion of biases in the CPI involve service prices, which also miss a lot of quality improvements, making the overall effect. Hobijn (20xx) also questions the hedonic adjustments in Gordon, Cummins, and Violante may be misleading.

${ }^{38}$ In steady-state, $I / K=g+\delta$. Since the right-hand-side is constant, $I$ must grow at the same rate as $K$.

${ }^{39}$ The mnemomics - Durables rather than Equipment, for example — is to clearly differentiate the output of producing sectors from the accumulated stock of equipment and structures. 
To solve for steady state growth rates, I follow Whelan (2003). In steady state, growth of equipment and structures must be the same in all uses, and labor growth (at rate $n$ ) is the same in all uses. Let $g_{X}$ be steady-state growth in variable $X$. In steady-state, the perpetual-inventory formula implies that growth of investment in equipment or structures is equal to growth in the capital stocks of equipment and structures, respectively. That is, $g_{E}=g_{D}$ and $g_{S}=g_{B}$. In growth rates, then:

$$
\begin{aligned}
& g_{D}=\alpha\left(c_{E} g_{D}+\left(1-c_{E}\right) g_{B}\right)+(1-\alpha)(\hat{a}+n) \\
& g_{B}=\alpha\left(c_{E} g_{D}+\left(1-c_{E}\right) g_{B}\right)+(1-\alpha)(\hat{a}+n)+\hat{q}_{S}=g_{D}+\hat{q}_{S} \\
& g_{C}=\alpha\left(c_{E} g_{D}+\left(1-c_{E}\right) g_{B}\right)+(1-\alpha)(\hat{a}+n)+\hat{q}_{C}=g_{D}+\hat{q}_{C}
\end{aligned}
$$

This is a straightforward system of simultaneous equations that yield:

$$
\begin{aligned}
& g_{D}=(\hat{a}+n)+\frac{\alpha\left(1-c_{E}\right)}{1-\alpha} \hat{q}_{B} \\
& g_{B}=g_{D}+\hat{q}_{S} \\
& g_{C}=g_{D}+\hat{q}_{C}
\end{aligned}
$$

Chain GDP growth is share-weighted growth in final expenditure categories. If $s_{D}$ is the finalexpenditure-share of durables and $s_{B}$ is the final-expenditure-share of buildings, then:

$$
\begin{aligned}
g & =s_{D} g_{D}+s_{B} g_{B}+\left(1-s_{D}-s_{B}\right) g_{C} \\
& =g_{D}+s_{B} \hat{q}_{B}+\left(1-s_{D}-s_{B}\right) \hat{q}_{C} \\
& =(\hat{a}+n)+\left[\frac{\alpha\left(1-c_{E}\right)}{1-\alpha}+s_{B}\right] \hat{q}_{B}+\left(1-s_{D}-s_{B}\right) \hat{q}_{C}
\end{aligned}
$$

Growth in output per unit of labor is then:

$$
g-n=\hat{a}+\left[\frac{\alpha\left(1-c_{E}\right)}{1-\alpha}+s_{S}\right] \hat{q}_{S}+\left(1-s_{D}-s_{B}\right) \hat{q}_{C}
$$

Standard TFP growth for each sector is not in labor-augmenting form, so it equals:

$$
\begin{aligned}
& \widehat{T F P_{D}}=(1-\alpha) \hat{a} \\
& \widehat{T F P_{B}}=(1-\alpha) \hat{a}+\hat{q}_{B}=\widehat{T F P_{D}}+\hat{q}_{B} \\
& \widehat{T F P_{C}}=(1-\alpha) \hat{a}+\hat{q}_{C}=\widehat{T F P_{D}}+\hat{q}_{C}
\end{aligned}
$$

Overall TFP growth in this economy is output growth less share-weighted input growth:

$$
\widehat{T F P}=g-\alpha\left(c_{E} g_{D}+\left(1-c_{E}\right) g_{B}\right)-(1-\alpha) n
$$

Using the second line of (28) and then substituting from (26), we find: 


$$
\begin{aligned}
\widehat{T F P} & =\left[g_{D}+s_{B} \hat{q}_{B}+\left(1-s_{D}-s_{B}\right) \hat{q}_{C}\right]-\alpha\left(g_{D}+\left(1-c_{E}\right) \hat{q}_{B}\right)-(1-\alpha) n \\
& =(1-\alpha) g_{D}-\alpha\left(1-c_{E}\right) \hat{q}_{B}+s_{S} \hat{q}_{B}+\left(1-s_{D}-s_{B}\right) \hat{q}_{C}-(1-\alpha) n \\
& =(1-\alpha)(\hat{a}+n)+\alpha\left(1-c_{E}\right) \hat{q}_{B}-\alpha\left(1-c_{E}\right) \hat{q}_{B}+s_{B} \hat{q}_{B}+\left(1-s_{D}-s_{B}\right) \hat{q}_{C}-(1-\alpha) n \\
& =\widehat{T F P_{D}}+s_{B} \hat{q}_{B}+\left(1-s_{D}-s_{B}\right) \hat{q}_{C}
\end{aligned}
$$

Note that aggregate TFP growth is also equal to share-weighted sectoral TFP growth from (30).

Define investment TFP growth, $\widehat{T F P}_{I}$, in terms of user cost (factor share) weights (rather than expenditure weights):

$$
\begin{aligned}
\widehat{T F P_{I}} & =c_{E} \widehat{T F P_{D}}+\left(1-c_{E}\right) \widehat{T F P_{B}} \\
& =\widehat{T F P_{D}}+\left(1-c_{E}\right) \hat{q}_{B}
\end{aligned}
$$

We can now write growth in output per unit of labor from (29) in terms of overall and investmentsector TFP growth:

$$
\begin{aligned}
g-n & =\hat{a}+\left[\frac{(1-\alpha) s_{B}+\alpha\left(1-c_{E}\right)}{1-\alpha}\right] \hat{q}_{B}+\left(1-s_{D}-s_{B}\right) \hat{q}_{C} \\
& =\left[(1-\alpha) \hat{a}+s_{B} \hat{q}_{B}+\left(1-s_{D}-s_{B}\right) \hat{q}_{C}\right]+\alpha \hat{a}+\left[\frac{(1-\alpha) s_{B}+\alpha\left(1-c_{E}\right)}{1-\alpha}-s_{B}\right] \hat{q}_{B} \\
& =\widehat{T F P}+\left(\alpha \hat{a}+\left[\frac{\alpha\left(1-c_{E}\right)}{1-\alpha}\right] \hat{q}_{B}\right) \\
& =\widehat{T F P}+\frac{\alpha}{1-\alpha} \widehat{T F P}
\end{aligned}
$$

Although the derivation is somewhat involved, this is exactly the same equation as for the two-sector model.

Finally, note that the existence of consumer durables (produced by the durable sector) does not affect this calculation. The weight on equipment in final expenditure, $s_{D}$, already includes all final uses of equipment output (whether for investment or for durable consumption). However, the user cost weight of equipment includes only the portion used for equipment investment.

\section{Adding inventories, consumer durables, and land}

In practice, there are not only multiple types of capital goods, but land. We can derive more general steady-state predictions using the same approach as with the three-sector model above. ${ }^{40}$

Specifically, we assume the same production structure as in (24), above:

${ }^{40}$ This analysis takes land as exogenous, though not fixed - it can be pulled from other uses, and in the BLS dataset, business use of land grows at about 1-1/2 percent per year. An alternative modeling strategy would be to tie it to the use of structures in some way. That said, the correlation in the BLS dataset between annual changes in structures and land is far from perfect (about 0.4). 


$$
\begin{aligned}
& D=\left(K_{D}\right)^{\alpha}\left(A N_{E}\right)^{1-\alpha} \\
& B=Q_{B}\left(K_{B}\right)^{\alpha}\left(A N_{B}\right)^{1-\alpha} \\
& C=Q_{C}\left(K_{C}\right)^{\alpha}\left(A N_{C}\right)^{1-\alpha}
\end{aligned}
$$

Now, some durable goods are used for consumption (which raises the weight of durables in final output). We also have inventories in capital. Inventories are goods (in the data, roughly half are durable and half are non-durable), but their relative price movements are less pronounced than for equipment. For generality in derivations, we'll allow both the durable and the non-durable sectors to produce inventories.

The capital aggregate now includes inventories, $V$, and land, $T$ (for Terra), as well as equipment and structures:

$$
K=E^{c_{E}} S^{1-c_{E}-c_{V}-c_{T}}\left(V_{D}^{\delta} V_{C}^{1-\delta}\right)^{c_{E}} T^{c_{T}}=K_{D}+K_{B}+K_{C}
$$

Using in (24) and (36), we can proceed in the same way as in the three-sector model:

$$
\begin{aligned}
& g_{D}=\alpha\left(c_{E} g_{D}+\left(1-c_{E}-c_{V}-c_{T}\right) g_{B}+c_{V} \delta g_{D}+c_{V}(1-\delta) g_{C}+c_{T} \hat{T}\right)+(1-\alpha)(\hat{a}+n) \\
& g_{B}=g_{D}+\hat{q}_{B} \\
& g_{C}=g_{D}+\hat{q}_{C}
\end{aligned}
$$

TFP growth in each sector is related to the "fundamental shocks" as shown in equation (30). TFP growth for "reproducible investment," $\widehat{T F P}_{I}$, with user cost (factor share) weights, is then:

$$
\begin{aligned}
\widehat{T F P_{I}} & =\left(\frac{c_{E}+c_{V} \delta}{1-c_{T}} \widehat{T F P_{D}}+\frac{\left(1-c_{E}-c_{V}-c_{T}\right)}{1-c_{T}} \widehat{T F P_{B}}+\frac{c_{V}(1-\delta)}{1-c_{T}} \widehat{T F P_{C}}\right) \\
& =\widehat{T F P_{D}}+\frac{\left(1-c_{E}-c_{V}-c_{T}\right)}{1-c_{T}} \hat{q}_{B}+\frac{c_{V}(1-\delta)}{1-c_{T}} \hat{q}_{C}
\end{aligned}
$$

Solving the system of equations in (37) yields

$$
g_{D}=\left(\frac{1-\alpha}{1-\alpha\left(1-c_{T}\right)}\right)(\hat{a}+n)+\frac{\alpha c_{V}(1-\delta)}{1-\alpha\left(1-c_{T}\right)} \hat{q}_{C}+\frac{\alpha\left(1-c_{E}-c_{V}-c_{T}\right)}{1-\alpha\left(1-c_{T}\right)} \hat{q}_{S}+\left(\frac{\alpha c_{T}}{1-\alpha\left(1-c_{T}\right)}\right) \hat{T}
$$


Adding and subtracting $\widehat{T F P_{D}}$, rearranging, and substituting from (38), yields:

$$
\begin{aligned}
g_{D} & =\widehat{T F P_{D}}+\left[\frac{1}{1-\alpha\left(1-c_{T}\right)}-1\right] \widehat{T F P_{D}}+\frac{\alpha c_{V}(1-\delta)}{1-\alpha\left(1-c_{T}\right)} \hat{q}_{C}+\frac{\alpha\left(1-c_{E}-c_{V}-c_{T}\right)}{1-\alpha\left(1-c_{T}\right)} \hat{q}_{S}+\left(\frac{\alpha c_{T}}{1-\alpha\left(1-c_{T}\right)}\right) \hat{T}+\left(\frac{1-\alpha}{1-\alpha\left(1-c_{T}\right)}\right) n \\
& =\widehat{T F P_{D}}+\left[\frac{\alpha\left(1-c_{T}\right)}{1-\alpha\left(1-c_{T}\right)}\right]\left[\widehat{T F P_{D}}+\frac{\left(1-c_{E}-c_{V}-c_{T}\right)}{1-c_{T}} \hat{q}_{S}+\frac{c_{V}(1-\delta)}{1-c_{T}} \hat{q}_{C}\right]+\left(\frac{\alpha c_{T}}{1-\alpha\left(1-c_{T}\right)}\right) \hat{T}+\left(\frac{1-\alpha}{1-\alpha\left(1-c_{T}\right)}\right) n \\
& =\widehat{T F P_{D}}+\left[\frac{\alpha\left(1-c_{T}\right)}{1-\alpha\left(1-c_{T}\right)}\right] \widehat{T F P_{I}}+\left(\frac{\alpha c_{T}}{1-\alpha\left(1-c_{T}\right)}\right) \hat{T}+\left(\frac{1-\alpha}{1-\alpha\left(1-c_{T}\right)}\right) n
\end{aligned}
$$

Growth in reproducible capital per worker can be expressed as:

$$
\begin{aligned}
\hat{K}^{\mathrm{R}}-n & =\left(\frac{1}{1-c_{T}}\right)\left(\left(c_{E}+c_{V} \delta\right) g_{D}+\left(1-c_{E}-c_{V}-c_{T}\right) g_{S}+c_{V}(1-\delta) g_{S}\right)-n \\
& =g_{D}+\left(\frac{c_{V}(1-\delta)}{1-c_{T}}\right) \hat{q}_{C}+\left(\frac{1-c_{E}-c_{V}-c_{T}}{1-c_{T}}\right) \hat{q}_{S}-n
\end{aligned}
$$

If we substitute for $\mathrm{g}_{\mathrm{D}}$ from(39) and rearrange, we find:

$$
\hat{K}^{\mathrm{R}}-n=\left[\frac{1}{1-\alpha\left(1-c_{T}\right)}\right] \widehat{T F P}+\left(\frac{\alpha c_{T}}{1-\alpha\left(1-c_{T}\right)}\right)(\hat{T}-n)
$$

Overall capital deepening is

$$
\begin{aligned}
\alpha(\hat{K}-n) & =\alpha\left(1-c_{T}\right)\left(\hat{K}^{\mathrm{R}}-n\right)+\alpha c_{T}(\hat{T}-n) \\
& =\left[\frac{\alpha\left(1-c_{T}\right)}{1-\alpha\left(1-c_{T}\right)}\right] \widehat{T F P_{I}}+\left(\frac{\alpha c_{T}}{1-\alpha\left(1-c_{T}\right)}\right)(\hat{T}-n)
\end{aligned}
$$

From (13), output per worker is:

$$
\begin{aligned}
g-n & =\widehat{T F P}+\alpha(\hat{K}-n) \\
& =\widehat{T F P}+\left[\frac{\alpha\left(1-c_{T}\right)}{1-\alpha\left(1-c_{T}\right)}\right] \widehat{T F P}+\left(\frac{\alpha c_{T}}{1-\alpha\left(1-c_{T}\right)}\right)(\hat{T}-n)
\end{aligned}
$$

This equation is a natural extension of the one- and two-sector models. If land's share, $c_{T}$, is zero, then this equation exactly matches (23) and (34). If $\widehat{T F P}=\widehat{T F P}$, then the equation matches (17).

In terms of comparing model projections, land is a complicating factor. Some comparisons are easier, however, since land affects the predictions equally. First, the predictions of the one-sector model with land are the case where $\widehat{T F P}=\widehat{T F P}$, so the difference in predictions (from (43))is just:

$$
\left(g^{\text {Multi-Sector }}-n\right)-\left(g^{\text {One Sector }}-n\right)=\left[\frac{\alpha\left(1-c_{T}\right)}{1-\alpha\left(1-c_{T}\right)}\right](\widehat{T F P}-\widehat{T F P}) \text {. }
$$


Second, recall from the second line of equation (28) that, by the definition of chained GDP, that $g=g_{D}+s_{B} \hat{q}_{B}+\left(1-s_{D}-s_{B}\right) \hat{q}_{C}$. It follows that components of the capital-output ratio are:

$$
\begin{aligned}
& g_{D}-g=s_{B} \hat{q}_{B}+\left(1-s_{D}-s_{B}\right) \hat{q}_{C} \\
& g_{B}-g=\left(g_{D}+\hat{q}_{B}\right)-g=\left(1-s_{B}\right) \hat{q}_{B}+\left(1-s_{D}-s_{B}\right) \hat{q}_{C} .
\end{aligned}
$$

Third, from equation (41) for growth in reproducible capital, and from the chain-GDP equation, it follows that the growth rate of the reproducible-capital-to-output ratio is:

$$
\hat{K}^{\mathrm{R}}-g=\left(\frac{1-c_{E}-c_{V}-c_{T}}{1-c_{T}}-s_{B}\right) \hat{q}_{B}+\left(\frac{c_{V}(1-\delta)}{1-c_{T}}-s_{C}\right) \hat{q}_{C}
$$

Note that the inventory share of non-land capital payments is under 10 percent, whereas $s_{C}$ is about 75 percent. Since $\hat{q}_{C}$ is negative in the data, the second piece tends to push growth in the reproduciblecapital to output ratio positive. On the other side, the weight on building-specific TFP growth is the difference between structure's weight in reproducible capital (which averages about 45 percent), and building's share of GDP (which averages 5 percent ). Since $\hat{q}_{B}$ is negative in the data, the building component tends to push this piece negative. 
Table 1

Historical Predictions of Growth Models

A. No Land

\begin{tabular}{|l|cc|cc|c|cc|}
\hline & $\begin{array}{c}\text { Overall } \\
\text { TFP }\end{array}$ & $\begin{array}{c}\text { Invest. } \\
\text { TFP }\end{array}$ & $\begin{array}{c}\text { One-Sector } \\
\text { Predicted } \\
\text { Y/L }\end{array}$ & $\begin{array}{c}\text { Multi-Sector } \\
\text { Predicted } \\
\text { Y/L }\end{array}$ & $\begin{array}{c}\text { Actual } \\
\text { Output per } \\
\text { Unit Labor }\end{array}$ & $\begin{array}{c}\text { Memo: } \\
\text { Labor } \\
\text { Quality }\end{array}$ & $\begin{array}{c}\text { Memo: } \\
\text { Actual } \\
\text { Output/Hour } \\
\text { (5)+(6) }\end{array}$ \\
\cline { 2 - 9 } & $\mathbf{( 1 )}$ & $\mathbf{( 2 )}$ & $\mathbf{( 3 )}$ & $\mathbf{( 4 )}$ & $\mathbf{( 5 )}$ & $\mathbf{( 6 )}$ & $\mathbf{( 7 )}$ \\
\hline \hline Full Sample & 1.3 & 1.8 & 1.9 & 2.2 & $\mathbf{2 . 0}$ & 0.4 & 2.4 \\
\hline pre-1973Q2 & 2.1 & 2.2 & 3.2 & 3.2 & $\mathbf{2 . 9}$ & 0.3 & 3.2 \\
1973Q2-1995Q4 & 0.4 & 1.0 & 0.7 & 0.9 & $\mathbf{1 . 0}$ & 0.4 & 1.4 \\
1995:Q4-2007:Q4 & 1.4 & 2.9 & 2.1 & 2.8 & $\mathbf{2 . 4}$ & 0.4 & 2.4 \\
\hline \hline
\end{tabular}

B. Adding Land as a Factor of Production

\begin{tabular}{|l|cc|cc|c|cc|}
\hline & $\begin{array}{c}\text { Overall } \\
\text { TFP }\end{array}$ & $\begin{array}{c}\text { Invest. } \\
\text { TFP }\end{array}$ & $\begin{array}{c}\text { One-Sector } \\
\text { Predicted } \\
\text { Y/L }\end{array}$ & $\begin{array}{c}\text { Multi-Sector } \\
\text { Predicted } \\
\text { Y/L }\end{array}$ & $\begin{array}{c}\text { Actual } \\
\text { Output per } \\
\text { Unit Labor }\end{array}$ & $\begin{array}{c}\text { Memo: } \\
\text { Labor } \\
\text { Quality }\end{array}$ & $\begin{array}{c}\text { Memo: } \\
\text { Actual } \\
\text { Output/Hour } \\
\text { (5)+(6) }\end{array}$ \\
\cline { 2 - 9 } & $\mathbf{( 1 )}$ & $\mathbf{( 2 )}$ & $\mathbf{( 3 )}$ & $\mathbf{( 4 )}$ & $\mathbf{( 5 )}$ & $\mathbf{( 6 )}$ & $\mathbf{( 7 )}$ \\
\hline \hline Full Sample & 1.3 & 1.8 & 1.9 & 2.1 & $\mathbf{2 . 0}$ & 0.4 & 2.4 \\
\hline pre-1973Q2 & 2.1 & 2.2 & 3.1 & 3.1 & $\mathbf{2 . 9}$ & 0.3 & 3.2 \\
1973Q2-1995Q4 & 0.4 & 1.0 & 0.6 & 0.8 & $\mathbf{1 . 0}$ & 0.4 & 1.4 \\
\hline
\end{tabular}

Notes: Column (3) shows predictions of one-sector growth model for output per unit of (quality-adjusted) labor. In panel A, that prediction depends on column (1) according to $\widehat{T F P} /(1-\alpha)$. Column (4) shows predictions of multi-sector growth model. In top panel, that depends on columns (1) and (2) according to $\widehat{T F P}+\alpha \cdot \widehat{T F P} /(1-\alpha)$ See text for how land is incorporated as a factor of production in bottom panel. The predictions are compared with actual output per unit of quality-adjusted labor in Column (5). The more typical output per hour is shown in Column (7). All calculations take capital's share $\alpha=0.33$, which is the full-sample average in the Fernald dataset. Investment TFP averages equipment TFP and structures TFP, where the weight on equipment includes the weight of inventories. 
Table 2

Projections for labor productivity (output per quality-adjusted hour)

\section{Scenarios}

- Optimistic: Durable Equipment and Consumption TFP grow at post-1995 rate, Buildings TFP is flat

- Benchmark: Use average growth rates since 1987:1

- Pessimistic: Use average growth rates since 2003:3

\begin{tabular}{|l|c|c|c|c|c|r|}
\hline & \multicolumn{2}{|c|}{ Exogenous TFP assumptions } & \multicolumn{2}{c|}{ Calculated TFP } & \\
\cline { 2 - 7 } & $\begin{array}{c}\text { Dur- } \\
\text { ables }\end{array}$ & $\begin{array}{c}\text { Buil- } \\
\text { dings. }\end{array}$ & $\begin{array}{c}\text { Consum- } \\
\text { ption }\end{array}$ & $\begin{array}{c}\text { Overall } \\
\text { TFP }\end{array}$ & $\begin{array}{c}\text { Invest. } \\
\text { TFP }\end{array}$ & $\begin{array}{l}\text { Implied } \\
\text { labor } \\
\text { prod. }\end{array}$ \\
\hline \hline Optimistic & 4.3 & 0.0 & 0.3 & 1.1 & 2.8 & 2.3 \\
\hline Benchmark & 3.6 & -0.3 & 0.2 & 0.9 & 2.2 & 1.9 \\
\hline Pessimistic & 3.3 & -0.6 & 0.0 & 0.5 & 2.0 & 1.3 \\
\hline
\end{tabular}

Notes: Percent per year. Expenditure weights in business output (used to calculate overall TFP from the exogenous TFP assumptions) use post-1995 values. User-cost weights (used to weight investment) are also post-1995 values. Calculations assume inventories are produced in the durable sector, that land's share of capital is 12 percent. The land-labor ratio is assumed to grow at 0.66 percent per year (Results are not very sensitive to this assumption.). 
Figure 1

Labor productivity since 1973

\section{Business Sector Labor Productivity}

Cumulative growth since 1973Q2

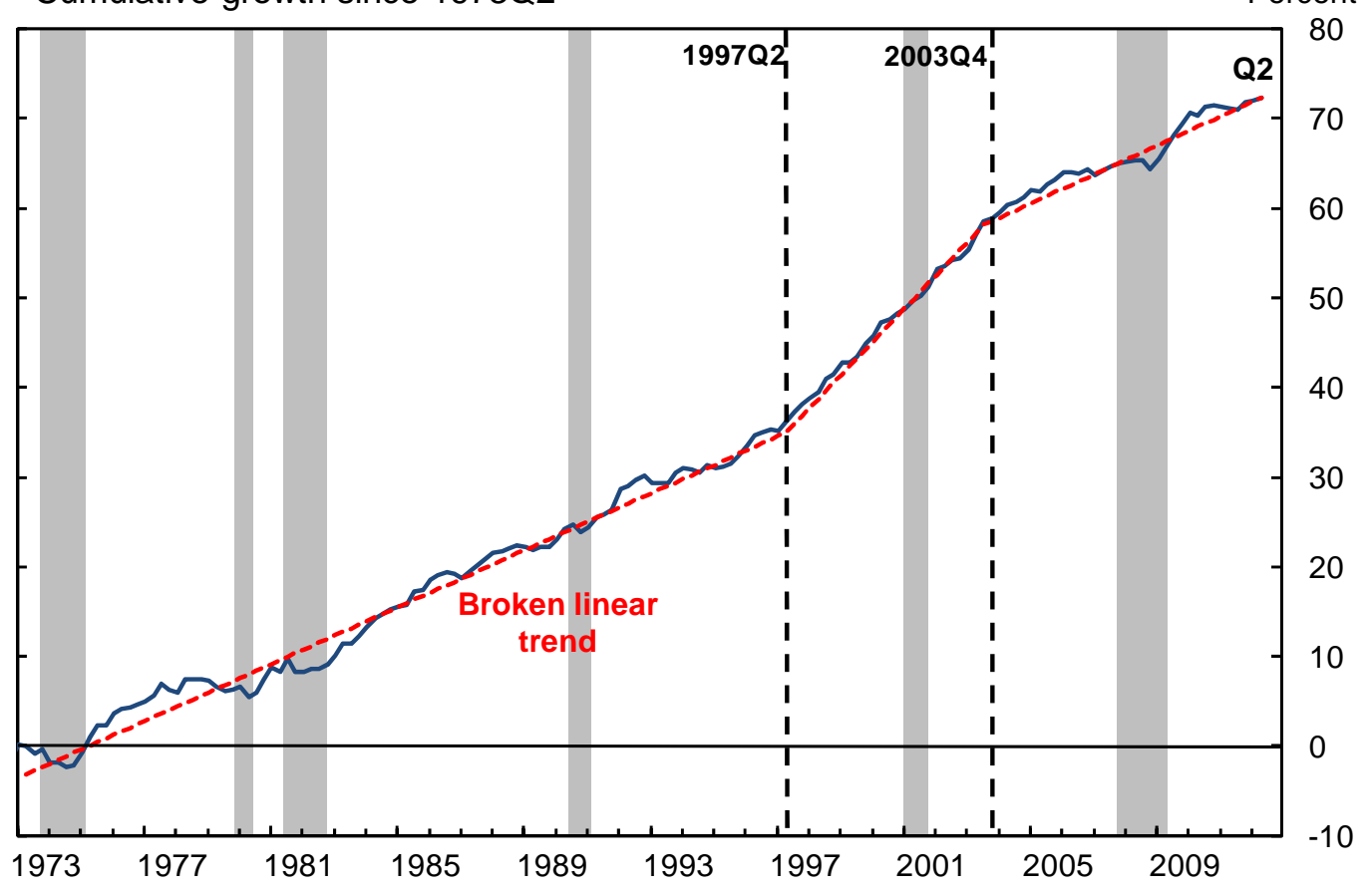

Source: BLS and Fernald (2012). 
Figure 2

Evolution of Key Growth-Accounting Variables

A. Total Factor Productivity

Cumulative growth rate since 1973 Q2

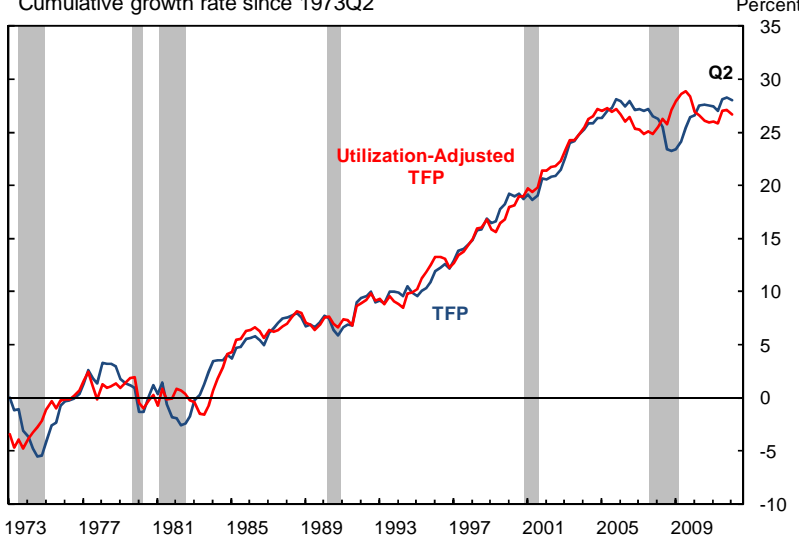

\section{Labor Quality}

Cumulative growth since 1973Q2

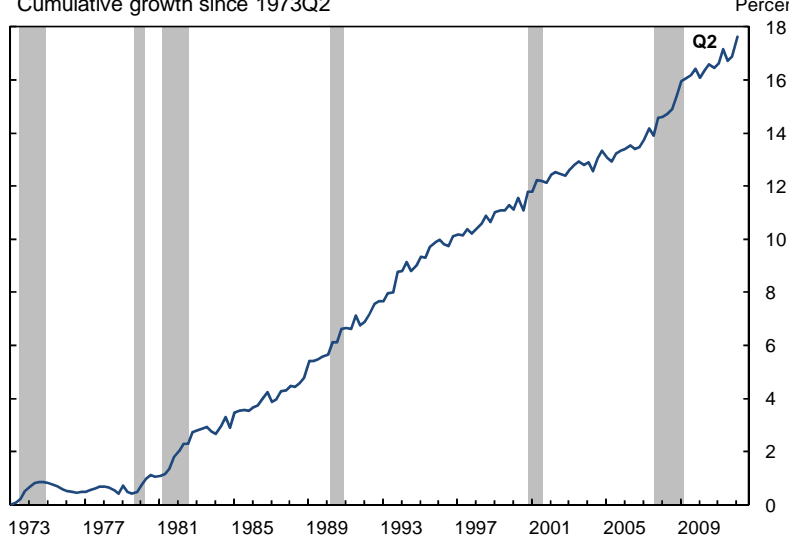

B. Quality-Adjusted Capital-Labor Ratio

Cumulative growth since 1973Q2 Percent

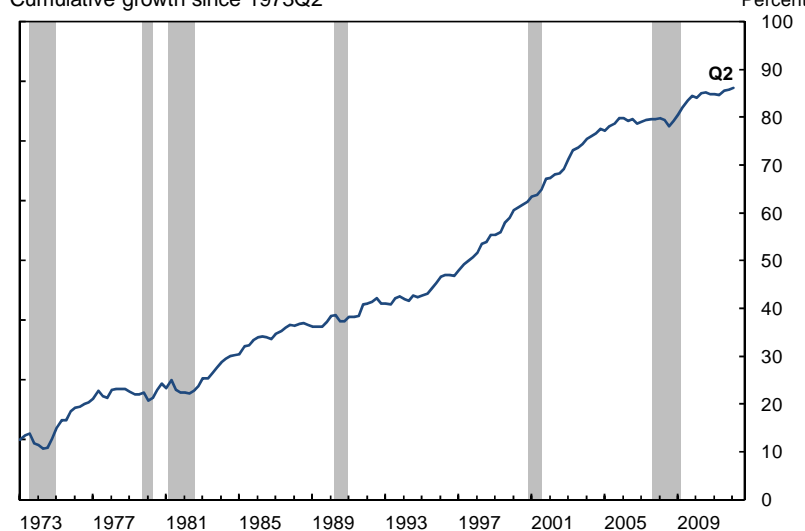

D. Utilization

Cumulative growth since 1973Q2

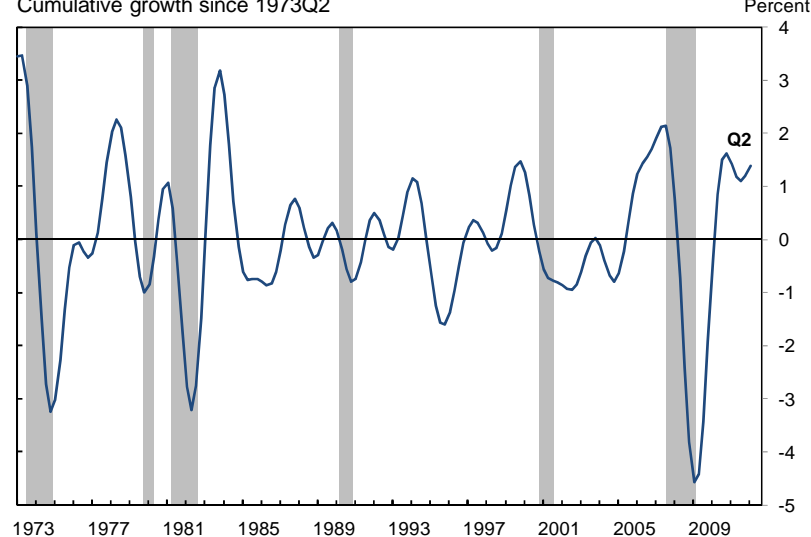

Notes: Mean of utilization set to zero for full sample that starts in 1973:2.

Source: Fernald (2012). 
Figure 3

Basu, Fernald, Oulton, and Srinivasan (2003) proxy for intangible investment

Share-Weighted Growth in Computers and Software

Capital's cost share of value added times capital growth, 4-qtr moving avg. Percent

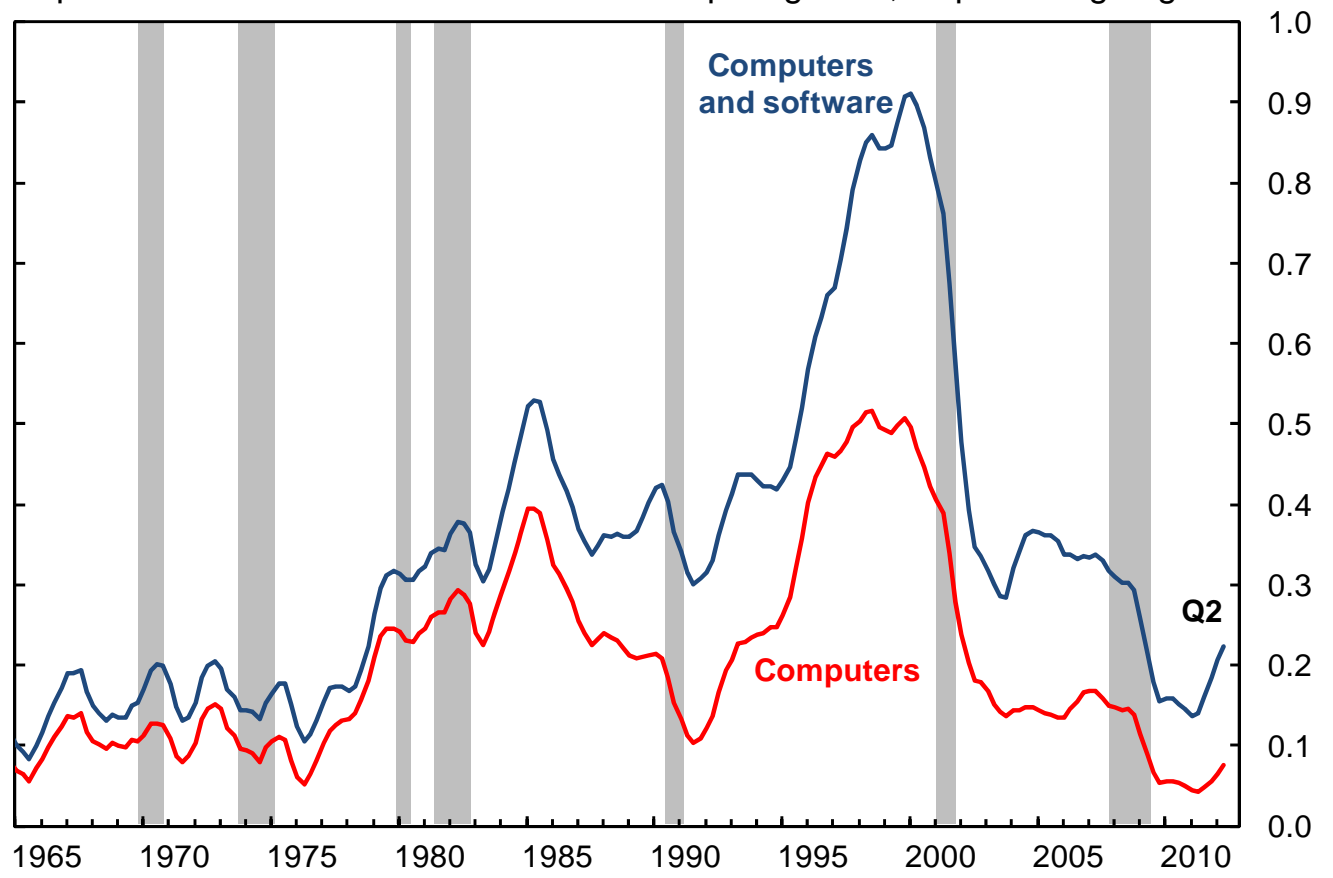

Source: BEA and Fernald (2012). 
Figure 4

Comparing Recessions: Main Variables (indexed to peak)

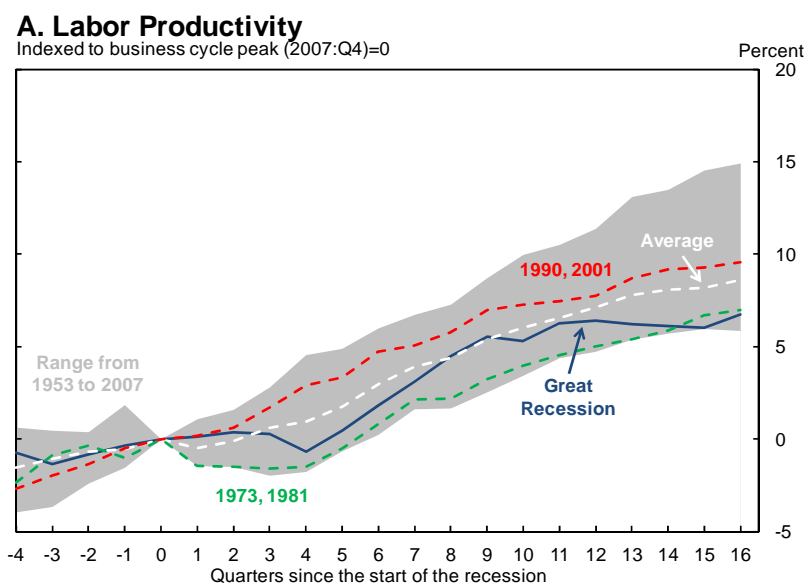

\section{B. Output}

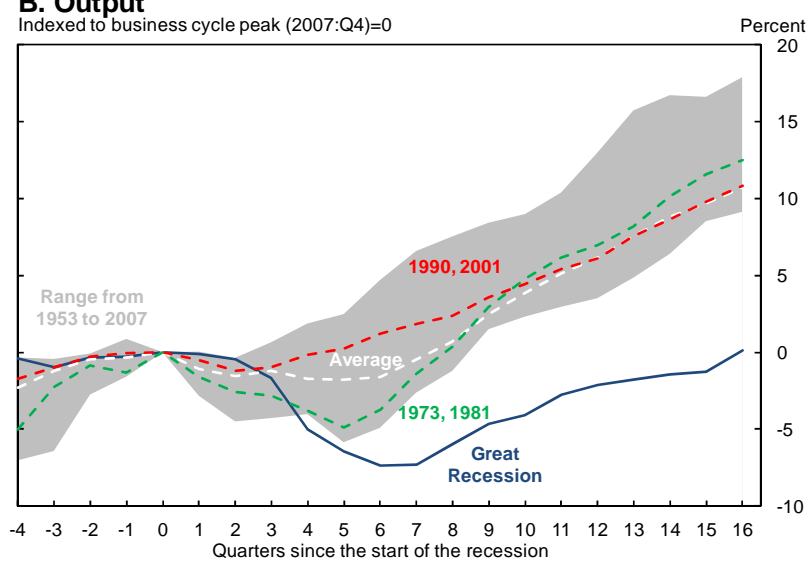

\section{Hours}

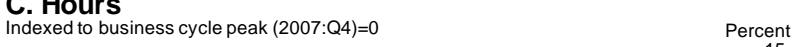

\section{Total Factor Productivity
Indexed to business cycle peak (2007:Q4)=0}

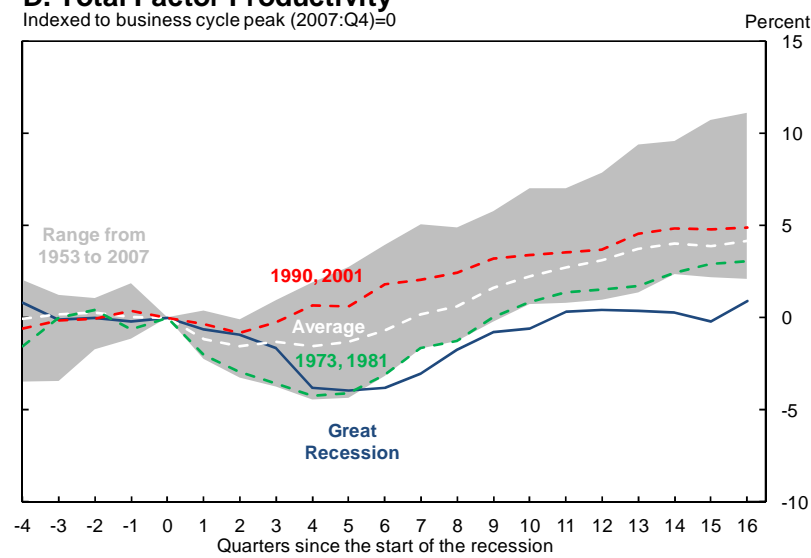

Note: For each plot, quarter 0 is the NBER business-cycle peak which, for the Great Recession, corresponds to 2007:Q4. The shaded regions show the range of previous recessions since 1953.

Source: Fernald (2012). 
Figure 5

Comparing Recessions: Additional Variables (indexed to peak)

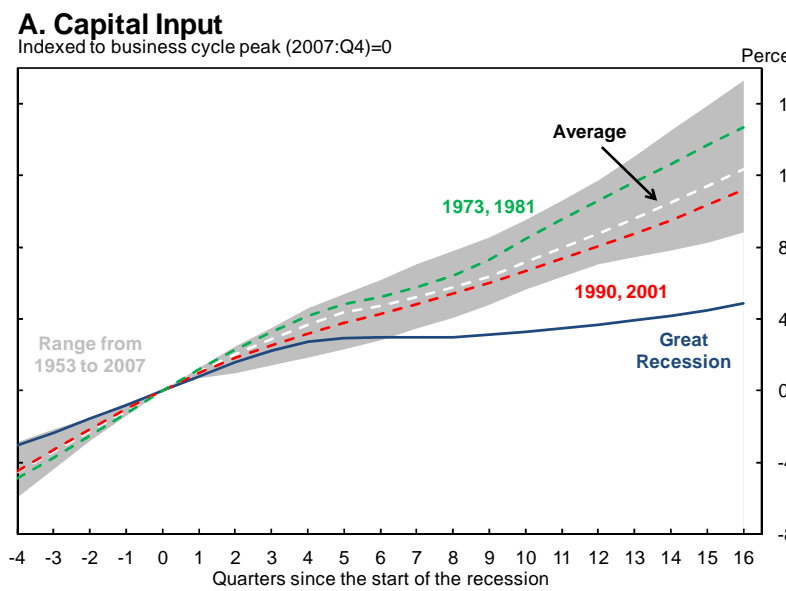

\section{B. Quality-Adjusted Capital-Labor Ratio}

Calculated as cumulated growth in capital less cumulated growth in labor; $\quad$ Percent Indexed to business cycle peak (2007:Q4)=0 15

\section{Labor Quality}

Indexed to business cycle peak (2007:Q4)=0 Percent
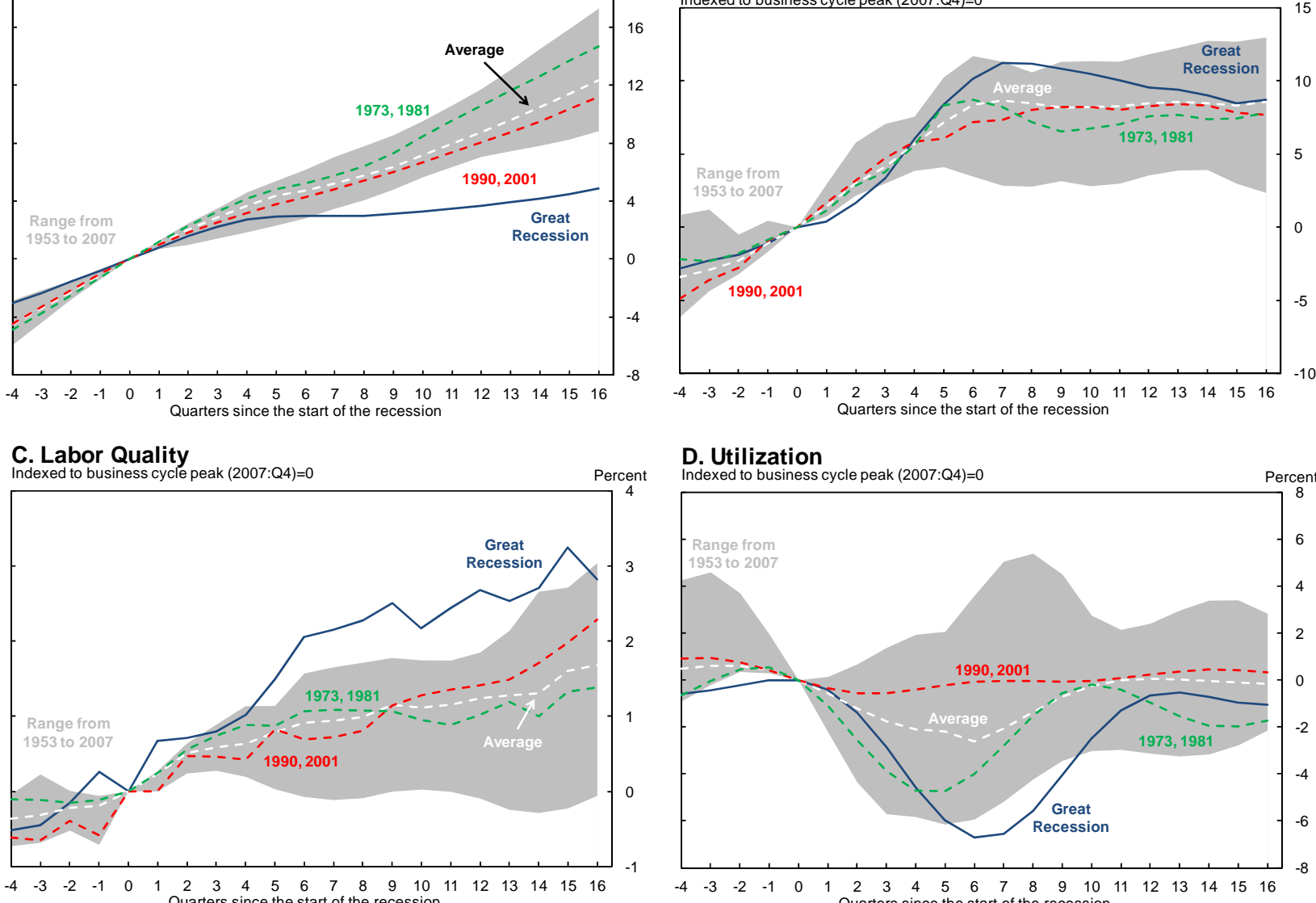

\section{Utilization}

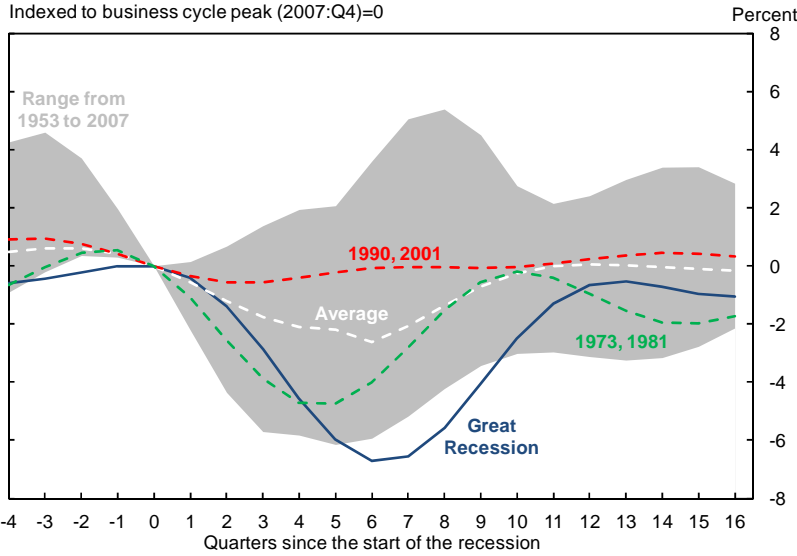

Note: For each plot, quarter 0 is the NBER business-cycle peak which, for the Great Recession, corresponds to 2007:Q4. The shaded regions show the range of previous recessions since 1953.

Source: Fernald (2012). 
Figure 6

Comparing recoveries: Selected Variables (indexed to trough)

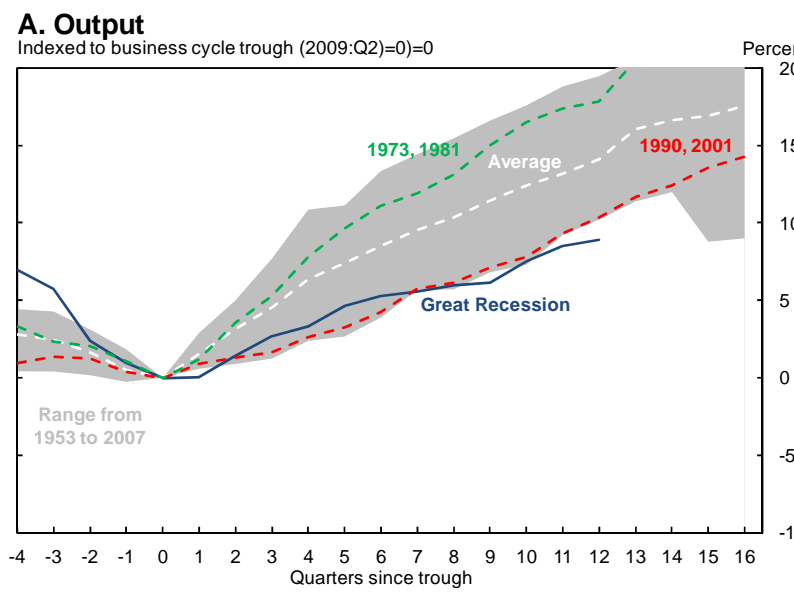

\section{B. Labor Productivity}

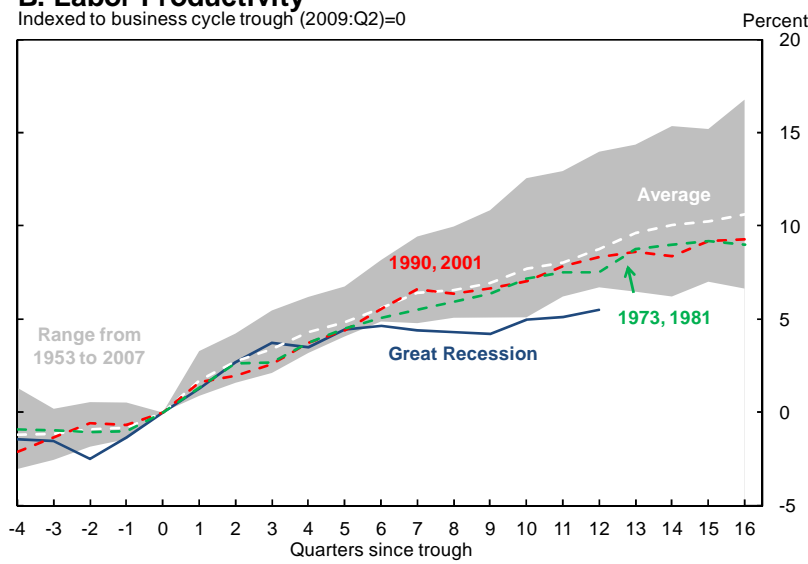

C. Total Factor Productivity
Indexed to business cycle trough (2009:Q2)=0

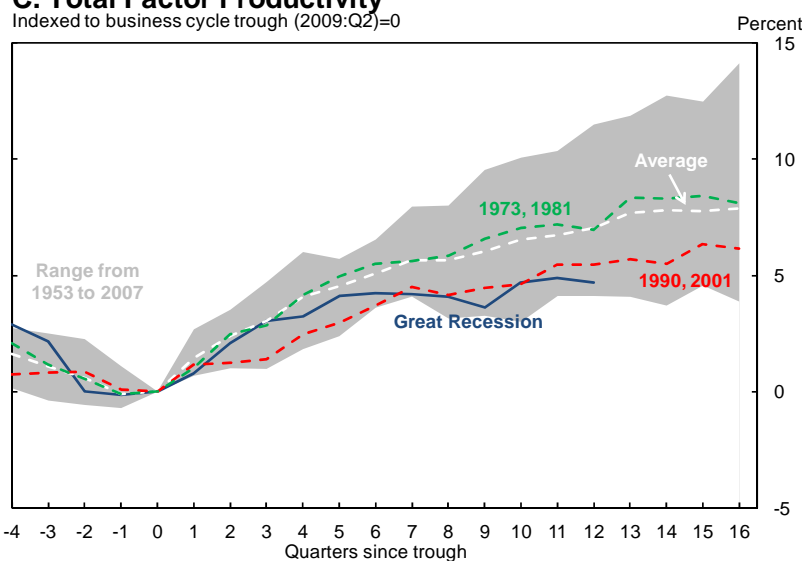

\section{Utilization}

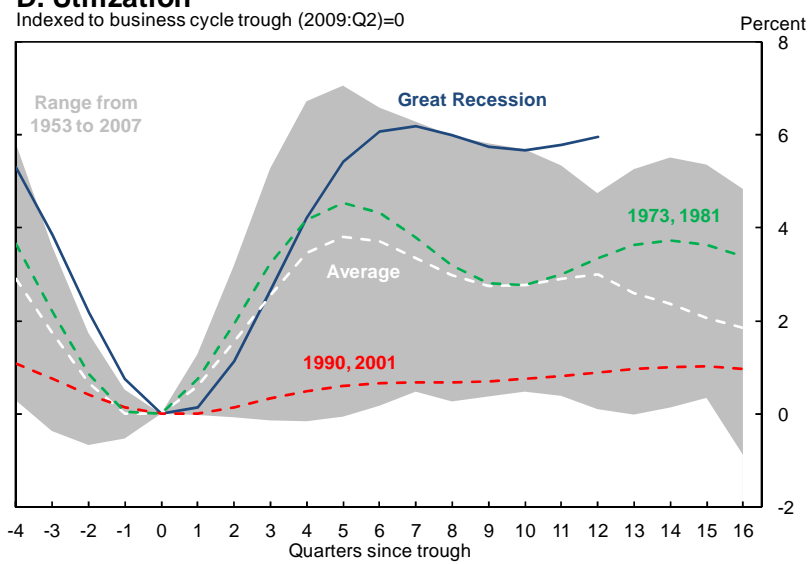

\section{E. Quality-Adjusted Capital-Labor Ratio}

Calculated as cumulated growth in capital less cumulated growth in labor;
Indexed to business cycle trough (2009:Q2) $=0$

F. Labor Quality
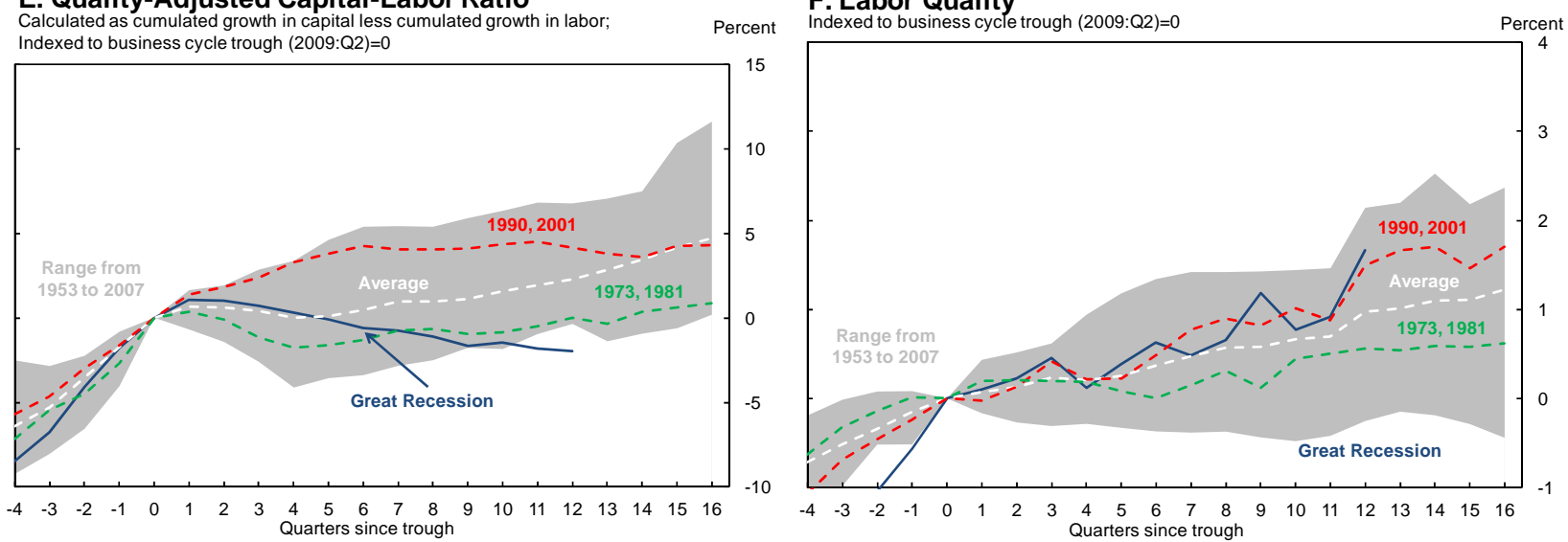

Note: For each plot, quarter 0 is the NBER business-cycle trough which, for the Great Recession, corresponds to 2009:Q2. The shaded regions show the range of previous recessions since 1953.

Source: Fernald (2012). 
Figure 7

Labor productivity revisions

\section{Labor Productivity Revisions}

Cumulative log change since 2003:Q4

Percent

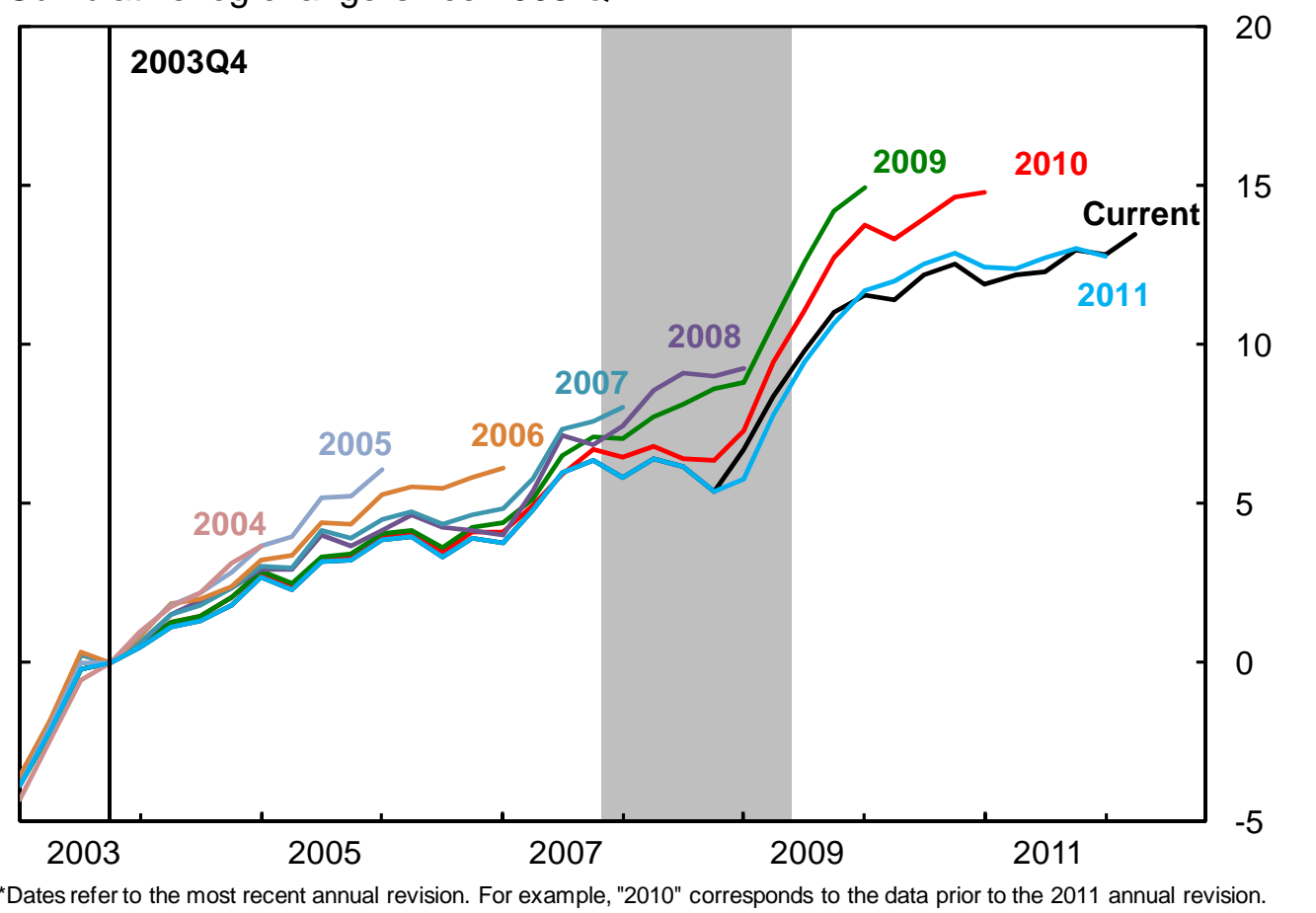

Source: BLS Productivity and Cost releases, and Haver. Output in these series correspond to the expenditure side of the national accounts rather than the average of the expenditure and income sides. 
Figure 8

TFP by final use sector

\section{TFP in equipment, structures, and consumption}

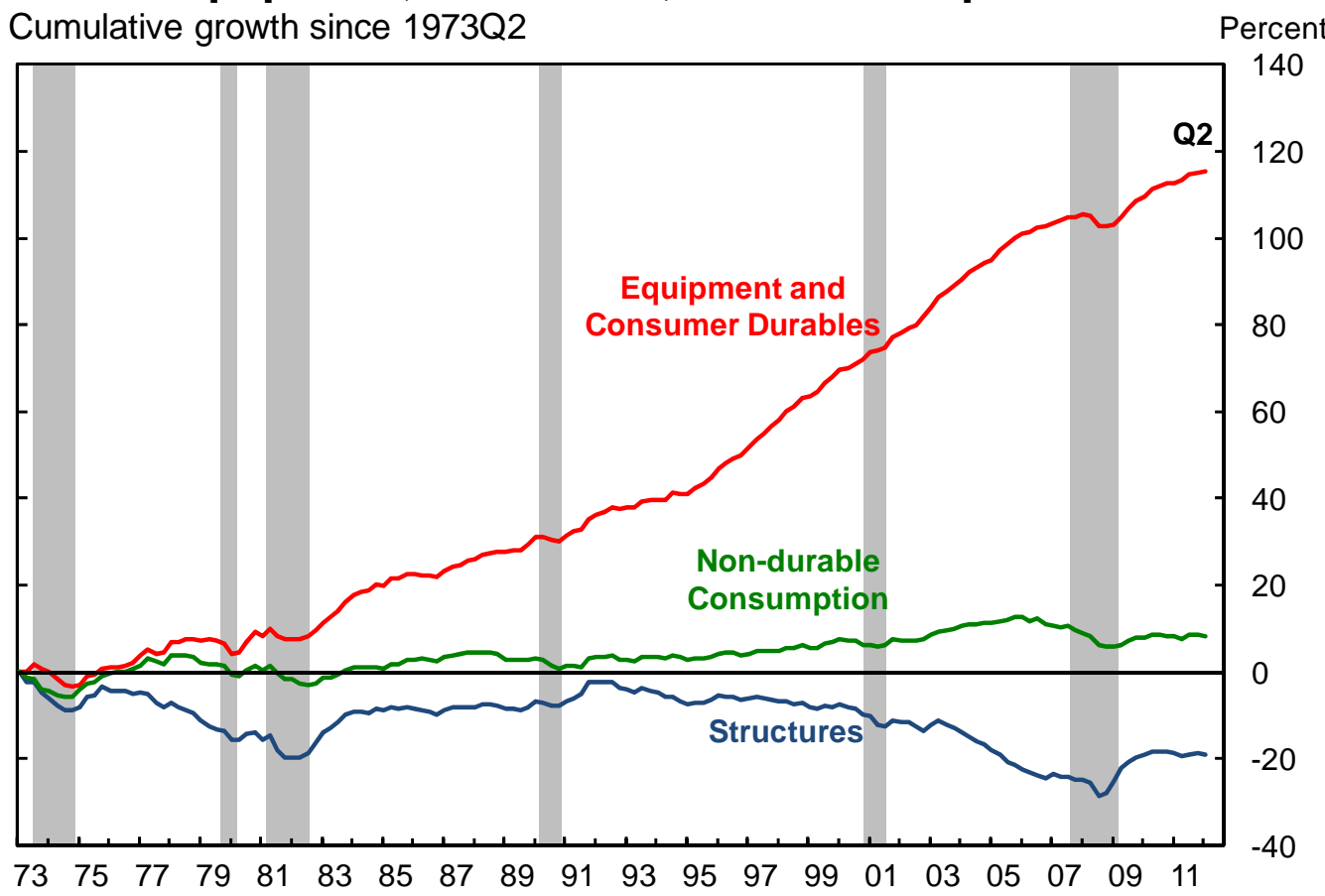

Source: Fernald (2012), BEA (for relative prices), and author's calculations. 
Figure 9

Potential Output and Its Pre-Crisis Trend

A. Capital Growth

Annualized quarterly log growth rate

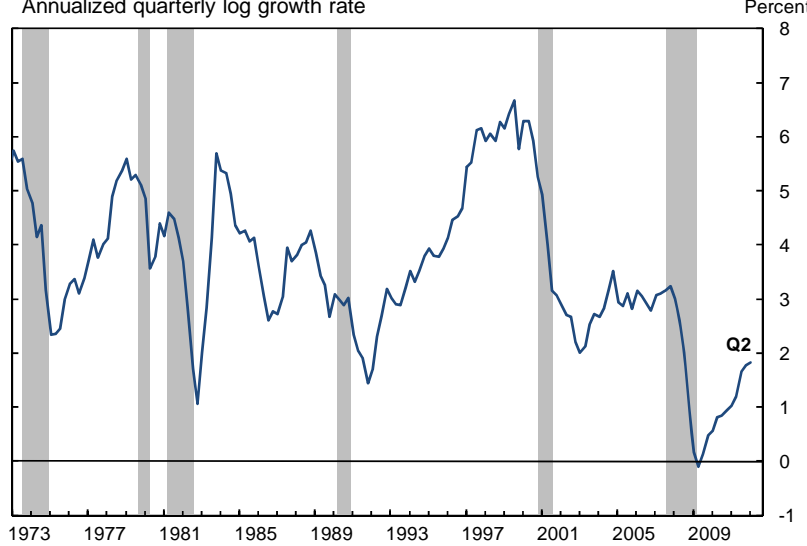

\section{B. Potential and Actual Real GDP}

Seasonally adjusted, $2005 \$$

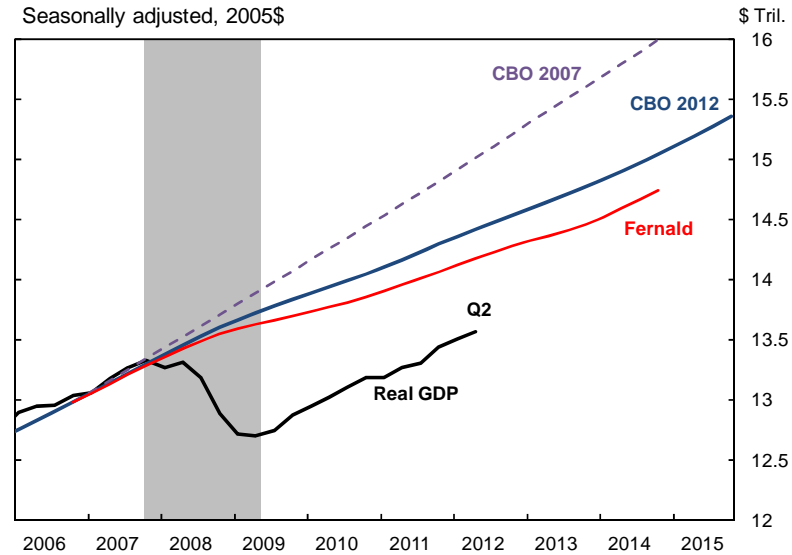

Notes: Figure A shows capital input growth from Fernald (2012). Panel B compares actual real GDP to the CBO's projections for potential prior to the Great Recession (the 2007 line), from August 2012, and the author's calculation of potential following the CBO methodology but with different assumptions about underlying technology and capital growth. 